\title{
Genetics, Cytogenetics, and Epigenetics of Colorectal Cancer
}

\author{
Lucia Migliore, ${ }^{1,2}$ Francesca Migheli, ${ }^{1}$ Roberto Spisni, ${ }^{3}$ and Fabio Coppedè ${ }^{1,2}$ \\ ${ }^{1}$ Department of Human and Environmental Sciences, University of Pisa, Street S. Giuseppe 22, 56126 Pisa, Italy \\ ${ }^{2}$ Istituto Toscano Tumori, 50139 Firenze, Italy \\ ${ }^{3}$ Department of Surgery, University of Pisa, 56126 Pisa, Italy
}

Correspondence should be addressed to Lucia Migliore, l.migliore@geog.unipi.it

Received 14 October 2010; Accepted 14 December 2010

Academic Editor: Nathan A. Ellis

Copyright (C) 2011 Lucia Migliore et al. This is an open access article distributed under the Creative Commons Attribution License, which permits unrestricted use, distribution, and reproduction in any medium, provided the original work is properly cited.

\begin{abstract}
Most of the colorectal cancer (CRC) cases are sporadic, only $25 \%$ of the patients have a family history of the disease, and major genes causing syndromes predisposing to CRC only account for 5-6\% of the total cases. The following subtypes can be recognized: MIN (microsatellite instability), CIN (chromosomal instability), and CIMP (CpG island methylator phenotype). CIN occurs in 80-85\% of CRC. Chromosomal instability proceeds through two major mechanisms, missegregation that results in aneuploidy through the gain or loss of whole chromosomes, and unbalanced structural rearrangements that lead to the loss and/or gain of chromosomal regions. The loss of heterozygosity that occur in the first phases of the CRC cancerogenesis (in particular for the genes on 18q) as well as the alteration of methylation pattern of multiple key genes can drive the development of colorectal cancer by facilitating the acquisition of multiple tumor-associated mutations and the instability phenotype.
\end{abstract}

\section{Introduction}

Worldwide, more than one million individuals develop colorectal cancer (CRC) each year, and the disease-specific mortality rate is nearly $33 \%$ in the developed world [1]. In Europe cancer of the gastrointestinal tract is the most common cancer: more than half of gastrointestinal cancer cases arise from the colon and around 250,000 new colon cases are diagnosed every year, accounting for around $9 \%$ of all the malignancies [2]. Colorectal cancer most commonly occurs sporadically, and only $25 \%$ of the patients have a family history of the disease, suggesting a contribution for shared genes and environment. However, only 5\%-6\% of CRC is due to inherited mutations in major CRC genes whilst the remaining of the familial forms likely result from geneenvironment interactions [3]. Rates of this cancer increase with industrialization and urbanisation, further indicating that environmental factors can likely represent risk factors. Diet is definitely the most important exogenous factor identified so far in the etiology of colorectal cancer.

CRC progresses through a series of clinical and histopathological stages ranging from single crypt lesions through small benign tumors (adenomatous polyps) to malignant cancers (carcinomas). Stages are usually defined by the tumor-node-metastasis (TNM) classification, as defined by the American Joint Committee on Cancer (AJCC). TNM is the most commonly used staging system and is based on depth of invasion of the bowel wall, extent of regional lymph node involvement, and presence of distant sites of disease. The depth of tumor invasion defines the $\mathrm{T}$ stage and increases from T1 (invasion of the submucosa) to T4 (invasion into the serosa or adjacent structures) [4]. Another grading system is Dukes classification that considers the arrangement of the cells rather than the percentage of the differentiated cells. The initial Dukes approach has evolved into the three-grade system. Grade 1 is the most differentiated, with well-formed tubules and the least nuclear polymorphism and mitoses. Grade 3 is the least differentiated, with only occasional glandular structures, pleomorphic cells and a high incidence of mitoses. Grade 2 is intermediate between Grades 1 and 3 [2].

The development of colorectal cancer is a multistep process that involves an accumulation of mutations in tumor suppressor genes and oncogenes. It has provided a useful model for the understanding of the multistep process of carcinogenesis. The model of colorectal tumorigenesis includes several genetic changes that are required for cancer initiation and progression [5]. The earliest trigger genetic event is 
the inactivation of the APC (adenomatous polyposis coli) pathway. Mutations in other tumor suppressor genes $(A P C$, SMAD2, 4, TP53) and oncogenes (KRAS) and likely several other genes/pathways accompany transitions in pathology of the lesions and drive tumor towards malignancy and metastasis [6]. Alongside with gene mutations a deregulated expression of oncogenes and/or tumor suppressor genes can also occur following epigenetic modifications of their promoters.

\section{Genetics of Colorectal Cancer}

Colorectal cancer represents the third most diagnosed cancer in both men and women. About $75 \%$ of the patients have sporadic forms of the disease. The remaining $25 \%$ of the patients have a family history of the disease, suggesting a contribution for shared genes and environment. However, only $5 \%-6 \%$ of CRC is due to highly penetrant inherited mutations in major genes, whilst the remaining of the familial forms likely result from interactions between less penetrant genes and environmental factors [3].

Several studies suggest that first degree relatives of an affected individual diagnosed after age 50 years have a twofold to threefold increased risk of colorectal cancer. Moreover, the number of affected family members and age at cancer diagnosis correlate with disease risk, suggesting that either having more than one first relative with colorectal cancer or a first relative individual diagnosed at an age below 45 years are conditions associated with a threefold to sixfold increased relative risk. When the family history includes two or more relatives with colorectal cancer, the possibility of a genetic syndrome is increased substantially $[3,7]$.

Other CRC risk factors include the presence of large serrated polyps (serrated adenomas and hyperplastic polyps), a diet rich in total fat and meat, cigarette smoking, male gender, the use of nonsteroidal anti-inflammatory drugs, alcohol intake, a sedentary lifestyle, body mass index (BMI) and abdominal obesity [8-12]. High intakes of folate, vitamins and dietary fiber, colonoscopy with removal of adenomatous polyps, and postmenopausal hormone use have been associated with decreased CRC risk [13-16].

2.1. Major CRC Genes and Syndromes. Some inherited conditions predispose an individual to the development of colorectal cancer. The study of these CRC syndromes has led to the identification of several major CRC genes (Table 1). Among major CRC genetic syndromes there are familial adenomatous polyposis (FAP), attenuated FAP (AFAP), MUTYH-associated polyposis (MAP), and Lynch syndrome (hereditary nonpolyposis colorectal cancer HNPCC). Rare syndromes include hamartomatous polyposis conditions (Peutz-Jeghers syndrome (PJS), juvenile polyposis syndrome (JPS), and others) and hyperplastic polyposis (Table 1).

2.1.1. Familial Adenomatous Polyposis (FAP), Attenuated FAP (AFAP), and Gardner Syndrome. FAP is an autosomal dominant condition characterized by the development of multiple (hundreds to thousands) adenomas in the rectum and colon after the first decade of life, that inevitably result in CRC development in untreated subjects. Males and females are equally likely to be affected. FAP accounts for less than $1 \%$ of CRC cases, with an estimated prevalence of 1/11,300-37,600 in the European Union [17]. FAP may present with some extraintestinal manifestations such as osteomas, dental abnormalities, congenital hypertrophy of the retinal pigment epithelium, and extracolonic tumours (desmoid tumors, stomach tumors, duodenum/small bowel tumors, thyroid cancers, pancreas tumors, hepatoblastoma, and central nervous system tumors) [3, 17]. Attenuated FAP (AFAP) is a less aggressive variant of FAP, characterized by fewer colorectal adenomatous polyps (usually 10 to 100), an average $69 \%$ lifetime risk of CRC, and later age of adenoma appearance. Some extracolonic tumors also occur in AFAP, including duodenum/periampullary and thyroid cancers [3, 17]. Gardner syndrome is a variant of FAP and results in the manifestation of numerous external and internal symptoms including gastrointestinal polyps, osteomas, dental anomalies, desmoid tumors, and epidermoid cysts [18]. FAP, attenuated FAP, and Gardner syndrome all result from germline mutations in the tumor suppressor Adenomatous Polyposis Coli $(A P C)$ gene on chromosome 5q21, which encodes a protein acting as an essential negative regulator in the evolutionarily conserved Wnt/Wingless $(\mathrm{Wg})$ signal transduction pathway [19]. Disease severity and the presence of extracolonic manifestations seem to be correlated with the location of the mutation within APC. Severe polyposis ( $>1000$ adenomas) is found in patients with mutations between codons 1250 and 1464. AFAP is correlated with mutations before codon 157, after codon 1595, and in the alternatively spliced region of exon 9. Mutations in the remainder of the $A P C$ gene cause an intermediate phenotype (hundreds to thousands of adenomas). Congenital hypertrophies of the retinal pigment epithelium and desmoid tumors are associated with mutations between codons 311 and 1444 and after codon 1444, respectively [20].

2.1.2. MUTYH-Associated Polyposis (MAP). MUTYH-associated polyposis (MAP) is an autosomal recessive disorder characterised by adenomatous polyps of the colorectum and a very high risk of colorectal cancer. It shares important gastroenterological features with autosomal dominant FAP. The colonic phenotype of MAP mimics AFAP, and the burden of adenomas ranges from very few to hundreds. Key extracolonic manifestations include a predisposition to duodenal adenomas and cancer and a modest increase in risk for several extraintestinal tumors $[3,21]$. The disease is caused by biallelic MUTYH mutations [22]. The Mut $Y$ homolog $(M U T Y H)$ gene, located on chromosome 1p, encodes a protein of the DNA base excision repair pathway whose impaired function leads to increased $\mathrm{G}: \mathrm{C}$ to $\mathrm{T}: \mathrm{A}$ transversions. The two common MUTYH variants observed in MAP patients are Tyr165Cys and Gly382Asp [22].

\subsubsection{Lynch Syndrome (Hereditary Nonpolyposis Colorectal Cancer or HNPCC). Lynch syndrome (LS), also known as} hereditary non-polyposis colorectal cancer or HNPCC, is 
TABLE 1: Major CRC genes and syndromes.

\begin{tabular}{lccc}
\hline Gene(s) & Syndrome & Inheritance & Lifetime CRC risk \\
\hline APC & FAP & Autosomal dominant & $100 \%$ \\
APC & AFAP & Autosomal dominant & $69 \%$ \\
MUTYH & MAP & Autosomal recessive & $80 \%$ \\
MLH1, MSH2, MSH6, PMS2, TACSTD1 (EPCAM) & LS & Autosomal dominant & $80 \%$ \\
STK11 & PJS & Autosomal dominant & $39 \%$ \\
SMAD4 (DPC4), BMPR1A & JPS & Autosomal dominant & $39 \%$ \\
PTEN & CS & Autosomal dominant & rare \\
\hline
\end{tabular}

an autosomal dominant condition caused by mutations in one of several DNA mismatch repair (MMR) genes and represents the most common hereditary CRC predisposing syndrome, accounting for approximately $3 \%$ of the total CRCs. Unlike FAP, polyposis is rare. Carriers of a Lynch syndrome gene mutation have an estimated $80 \%$ lifetime risk of developing CRC [23]. Colon cancers are most likely to develop in the right side, they frequently show mucinous or signet ring cell morphology, are characterized by lymphoid aggregates at the periphery of the tumor and/or lymphocytes infiltrating the tumor, and have an elevated frequency of microsatellite instability [23]. In addition to CRC, patients with Lynch syndrome and their relatives are at increased risk for several types of cancers, including endometrial adenocarcinoma and gastric, ovarian, biliary, urinary tract, small bowel, brain, and pancreatic cancers [3]. Muir-Torre syndrome (MTS) is considered a variant of Lynch syndrome; it is a rare disorder characterized by the presence of at least one sebaceous gland neoplasm and at least one visceral malignancy. Sebaceous adenomas, sebaceous carcinomas, and sebaceous epitheliomas are all characteristic glandular tumors of MTS. The most common visceral malignancies associated with MTS are colorectal, followed by genitourinary. These visceral malignancies frequently have a more indolent course in patients with MTS than they would otherwise. Muir-Torre syndrome is an autosomal dominant disorder, often associated with germline mutations in the MSH2, and the MLH1 genes [24]. The genes responsible for Lynch syndrome include MSH2 (mutS homolog 2) on chromosome 2p16, MLH1 (mutL homolog 1) on chromosome 3p21, MSH6 (mutS homolog 6) on chromosome 2p16, and PMS2 (postmeiotic segregation 2) on chromosome $7 \mathrm{p} 22$. These genes encode for MMR proteins that correct base mismatches or small insertions or deletions occurring during DNA replication. Their mutations in Lynch syndrome individuals account for the microsatellite instability observed in tumor cells. MSH2 and MLH1 mutations account for most of the cases of Lynch syndrome, and several recurrent or founder mutations have been identified in these two genes. For example the founder mutation in Ashkenazi Jews (MSH2 1906G>C), a genomic deletion of exon 16 of MLH1 that probably dates back 1000 years or more and accounts for $>50 \%$ of all Lynch syndrome in Finland, a genomic deletion of exons 1-6 of MSH2 in German American populations, and the recurrent $\mathrm{A} \rightarrow \mathrm{T}$ transversion in the donor splice site of intron 5 of MSH2 (designation c.942+
$3 \mathrm{~A} \rightarrow \mathrm{T}$ ), that occurs worldwide and may account for as much as $5 \%-10 \%$ of all Lynch syndrome (for a review see [23]). MTS is often associated with germline $\mathrm{MSH} 2$ or MLH1 mutations, though sporadic cases are known [24]. In addition to $M S H 2, M L H 1, M S H 6$, and PMS2 mutations, little evidence suggests that some cases of Lynch syndrome might be due to germline $M L H 3$ variants $[25,26]$. Recently, germline deletions in the TACSTD1 gene (also known as epithelial cell adhesion molecule gene: EPCAM) have been identified in families with Lynch syndrome resulting in multiple TACSTD1/MSH2 fusion transcripts and epigenetic inactivation of the corresponding $\mathrm{MSH} 2$ allele $[27,28]$.

\subsubsection{Hamartomatous Polyposis Conditions: Peutz-Jeghers} Syndrome, Juvenile Polyposis Syndrome, Mixed Polyposis Syndrome, and Others. Peutz-Jeghers syndrome (PJS) is an inherited, autosomal dominant disorder distinguished by hamartomatous polyps in the gastrointestinal tract and pigmented mucocutaneous lesions, typically presenting in childhood on the lips, buccal mucosa, and perioral region. Prevalence of PJS is estimated from 1 in 8300 to 1 in 280,000 individuals. PJS predisposes sufferers to various malignancies (gastrointestinal, pancreatic, lung, breast, uterine, ovarian and testicular tumors) $[29,30]$. The majority of patients that meet the clinical diagnostic criteria have a causative mutation in the tumor suppressor STK11 gene, located at 19p13.3, encoding a serine threonine kinase (STK) protein [31].

Juvenile polyposis syndrome (JPS) is a rare, early-onset disease, characterized by the presence of hamartomatous polyps throughout the gastrointestinal tract [32]. The lifetime CRC risk in JPS individuals is estimated to be $39 \%$ [33]. It is estimated that $15 \%-20 \%$ of JPS patients carry autosomal dominant mutations in the SMAD4/DPC4 (deleted in pancreatic cancer locus 4) gene, on chromosome $18 \mathrm{q} 21.1$, that encodes a critical cytoplasmic mediator in the transforming growth factor-beta signaling pathway [34], whereas $25 \%-40 \%$ of the patients carry autosomal dominant mutations in the gene encoding bone morphogenetic protein receptor 1A (BMPR1A), on chromosome 10q22-23 [35]. The rest of JPS cases appear to be sporadic.

Hereditary mixed polyposis syndrome (HMPS) is characterized by polyps of mixed adenomatous/hyperplastic/ atypical juvenile histology that are autosomal dominantly inherited and that eventually lead to colorectal cancer. There is consistent phenotypic overlap between JPS and HMPS. A recent study showed that germline BMPR1A defect is the 
CRC causing mutation in 50\% of Singapore Chinese HMPS families [36]. Linkage between HMPS and chromosome 15q has also been reported [37].

Cowden syndrome (CS) is another rare autosomal dominant hamartomatous polyposis condition. $27 \%-43 \%$ of CS patients have been shown to have hamartomatous polyps in the gastrointestinal tract; however, CS seems to confer little, if any, CRC risk [32]. The disease is caused in most of the cases by mutations of the tumor suppressor phosphatase and tensin homolog (PTEN) gene [38].

2.1.5. Hyperplastic Polyposis Syndrome (HPPS). HPPS is a rare condition characterized by the presence of multiple and/or large hyperplastic polyps throughout the colon that predisposes $50 \%$ or more of the patients to CRC development [39]. The World Health Organization (WHO) established that the diagnosis of HPPS must accomplish one of the following criteria: (1) at least five hyperplastic polyps occurring proximal to the sigmoid colon (of which at least two should be larger than $10 \mathrm{~mm}$ in diameter); (2) More than 30 hyperplastic polyps distributed throughout the colon; (3) at least one hyperplastic polyp proximal to the sigmoid colon in an individual who has at least one first-degree relative with HPPS [40]. Little is still known about the etiology and the genetics of this condition.

2.1.6. Familial Colorectal Cancer (FCC). As detailed in the introduction of this section, a family history of colorectal cancer (i.e., one or more relatives with CRC) confers a twofold to sixfold increased CRC risk, depending on the number of affected family members and the age at diagnosis of the affected relatives. Even if it is estimated that familial clusters of CRC account for almost $20 \%$ of CRCs in developed countries, the rare CRC syndromes described above contribute only to a fraction of them, suggesting the existence of other less penetrant genes and/or gene-environment interactions at the basis of familial CRC aggregates The term familial colorectal cancer (FCC) is used to categorize CRC families that do not meet the clinical criteria for a diagnosis of known hereditary CRC syndromes. Several approaches have been performed to identify less penetrant loci that might contribute to familial CRC, including family linkage, affected relative pair studies, and genome-wide association studies. Some of these studies have identified potential loci on chromosomes $8,9,11$, and 18 (see the review by Jasperson et al. [3], and the next section).

2.2. Genetic Polymorphisms and Colorectal Cancer Risk. Polymorphisms underlying genetic susceptibility to CRC have been investigated either by means of the classical candidate gene approach (based on the known function of the gene and its relevance in pathways likely involved in CRC pathogenesis) or, more recently, by means of genomewide association studies (GWAS) where half a million or more single nucleotide polymorphisms (SNPs) are tested simultaneously in a large case-control cohort. A continuously updated overview of the genetic polymorphisms associated with CRC risk can be found at the NCI website (http://www.cancer.gov/cancertopics/genetics/colorectal/ healthprofessional). Table 2 lists some examples of genes and loci associated with CRC risk.

2.2.1. Candidate Gene Approaches and Meta-Analyses. Sporadic $C R C$ is considered to be a multifactorial disease, in which multiple exposures to endogenous factors interact with individual genetic background in a complex manner, resulting in modulation of the risk. Several genes have been investigated as candidate CRC risk factors, often with conflicting or inconclusive results, and meta-analyses or updated reviews of the literature are currently available. Glutathione S-transferases (GSTs) are particularly attractive candidates for CRC susceptibility because they code enzymes involved in the metabolism of environmental carcinogens; recent meta-analyses of the literature suggest that both GSTM1 and GSTT1 null genotypes are associated with an increased risk of CRC, especially in the Caucasian populations [41-43]. Conflicting results have been obtained concerning DNA repair gene polymorphisms and CRC risk [44-46]. Cyclooxygenase-2 (COX2), a key enzyme in arachidonic acid metabolism, is overexpressed in several epithelial malignancies including colorectal cancer, and recent meta-analyses revealed that promoter polymorphisms of the COX2 gene may be potential risk factors for cancers of the digestive tract in Asians, including colorectal cancer [4749]. Polymorphisms of genes involved in folate metabolism, such as methionine synthase (MTR) and methylenetetrahydrofolate reductase (MTHFR), might also increase CRC risk [50, 51]. Interaction between smoking status and $\mathrm{N}$ acetyltransferases (NAT1 and NAT2) polymorphisms seem to affect CRC risk [52]. TGF-beta1, its receptor TGFbetaRII, and the signaling proteins Smad4 and Smad7 have been observed in the majority of colorectal cancer tissues [53]. Conflicting results have been obtained concerning TGFbeta receptor I (TGFBR1) polymorphisms and CRC risk [54], whilst increased risk of colon cancer was associated with variants of SMAD7 in several studies [55-58]. The I1307K polymorphism in the APC gene occurs almost exclusively in Ashkenazi Jews and increases the risk of colorectal cancer [59]. Some polymorphisms also affect the phenotype of Lynch syndrome (HNPCC). For example, age at onset of CRC in HNPCC is modified by a promoter polymorphism of the insulin-like growth factor gene (IGF1) [60,61].

2.2.2. Genome-Wide Association Studies (GWAS). Large genome-wide association studies (GWAS) identified several loci as possible common low-risk susceptibility alleles, including 8q23.3, 8q24, 10p14, 11q23, 15q13, and 18q21 [62, 63]. A meta-analysis of those GWAS revealed four additional susceptibility loci on 14q22.2, 16q22.1, 19q13.1, and 20p12.3, in addition to the six loci previously identified [64]. A recent GWAS in German familial CRC cases confirmed the two previously reported loci at 8q24 and 11q23, and suggested novel polymorphisms (rs12701937, rs6038071, and rs11014993) associated with CRC in familial cases [65].

2.3. Genes Involved in CRC Progression: TP53 and K-RAS. Mutations in TP53 and K-RAS do not cause CRC syndromes, 
TABLE 2: Some of the genes or loci associated with CRC risk (see the text for details).

\begin{tabular}{|c|c|c|}
\hline Gene or locus & Type of study & Comment \\
\hline GSTT1 & Meta-analysis of genetic association studies & $\begin{array}{l}\text { GSTT1 null genotype associated with increased CRC } \\
\text { risk (Caucasians) }\end{array}$ \\
\hline GSTM1 & Meta-analysis of genetic association studies & $\begin{array}{l}\text { GSTM1 null genotype associated with increased CRC } \\
\text { risk (Caucasians) }\end{array}$ \\
\hline COX2 & Meta-analysis of genetic association studies & $\begin{array}{l}\text { Promoter polymorphisms associated with increased } \\
\text { CRC risk (Asians) }\end{array}$ \\
\hline MTHFR & Meta-analysis of genetic association studies & MTHFR $677 \mathrm{C}>\mathrm{T}$ associated with increased CRC risk \\
\hline NATs & Gene-environment interaction & $\begin{array}{l}\text { Interaction between NATs polymorphisms and smoking } \\
\text { status affect CRC risk }\end{array}$ \\
\hline MTR & Meta-analysis of genetic association studies & MTR 2756A $>\mathrm{G}$ associated with increased CRC risk \\
\hline SMAD7 & Genetic association studies and GWAS & SMAD7 variants associated with increased CRC risk \\
\hline$A P C$ & Genetic association studies & $\begin{array}{l}\text { APC I1307K associated with increased CRC risk in } \\
\text { Ashkenazi Jews }\end{array}$ \\
\hline IGF1 & Genetic association studies & $\begin{array}{l}I G F 1 \text { promoter polymorphisms associated with } \\
\text { HNPCC age at onset }\end{array}$ \\
\hline $8 \mathrm{q} 23.3$ & GWAS & Associated with CRC risk \\
\hline $8 \mathrm{q} 24$ & GWAS & Associated with CRC risk \\
\hline $10 \mathrm{p} 14$ & GWAS & Associated with CRC risk \\
\hline $11 \mathrm{q} 23$ & GWAS & Associated with CRC risk \\
\hline $15 \mathrm{q} 13$ & GWAS & Associated with CRC risk \\
\hline $14 \mathrm{q} 22.2$ & Meta-analysis of GWAS & Associated with CRC risk \\
\hline $16 \mathrm{q} 22.1$ & Meta-analysis of GWAS & Associated with CRC risk \\
\hline $18 \mathrm{q} 21$ & GWAS & Associated with CRC risk \\
\hline $19 \mathrm{q} 13.1$ & Meta-analysis of GWAS & Associated with CRC risk \\
\hline $20 \mathrm{p} 12.3$ & Meta-analysis of GWAS & Associated with CRC risk \\
\hline
\end{tabular}

however; they are the genetic abnormalities most exhaustively implicated and studied in CRC progression. TP53 encodes a transcription factor (p53) defined as the "guardian of the genome" since it is involved in the coordination of cellular responses to oxidative stress, DNA damage, cell cycle regulation, apoptosis, and many other pathways. Loss of TP53 function through gene mutation is a critical event in the development and progression of many tumour types including CRC. The majority of TP53 mutations occur in the core domain which contains the sequence-specific DNA binding activity of the protein, and they results in loss of DNA binding. Inactive TP53 mutations were found in $29 \%$ of all CRCs and were more frequent in rectal than proximal colon tumours. TP53 mutations were associated with lymphatic invasion in proximal tumors, and with worse survival in distal tumors. Higher frequencies of inactive TP53 mutations were also seen in advanced-stage tumours and in tumours with the poor prognostic features of vascular and lymphatic invasion. Inactive TP53 mutations have been associated with significantly worse outcome only in patients with Dukes stage D tumours [66, 67].

The RAS signalling pathway is involved in growth differentiation, cell survival, cell proliferation, apoptosis, cytoskeleton organization and function, inflammation, and cell transformation. A glycine to valine mutation on codon 12 of $K-R A S$, found in $8.6 \%$ of all patients, had a statistically significant impact on failure-free survival and overall survival. This mutation also appeared to have a greater impact on outcome in Dukes' C cancers than in Dukes' B tumours. The study demonstrated that not only is the presence of a codon 12 glycine to valine mutation important for cancer progression, but also that it may predispose to more aggressive biological behaviour in patients with advanced colorectal cancer [68].

\section{Cytogenetics of Colorectal Cancer: The CIN Phenotype}

For colorectal cancers, the acquisition of genomic instability is considered a key hallmark. Three major molecular subtypes can be recognized: MIN (or MSI, for "microsatellite instability"), CIN (for "chromosomal instability") and CIMP (for "CpG island methylator phenotype") [79, 80]. MIN CRC accounts for approximately $15 \%-20 \%$ of sporadic colorectal cancers. It is a well-defined subtype that results from a loss of DNA mismatch repair function, secondary to inactivation of MMR genes (see Lynch syndrome, Section 2.1.3). MIN tumors were at the beginning believed to be near-diploid with few, if any, karyotypic abnormalities [77]. However in MSI tumors, the pathway of chromosome gains is frequently observed whereas that of chromosomal losses is rarely found [75]. On the other hand the definitions of the three pathways (MIN, CIN, and CIMP) are not completely 
TABLE 3: The most frequent aberrations found in CRC (see the text for details).

\begin{tabular}{|c|c|c|}
\hline Chromosome loss & Chromosome gain & References \\
\hline $18,17 \mathrm{p}, 1 \mathrm{p}, 4,14,5 \mathrm{q}, 21$ & $7,12, X, 5,8$ & Dutrillaux, 1988 [69] \\
\hline \multirow[t]{2}{*}{$18 \mathrm{q} 21$} & & Fearon et al., 1990 [70] \\
\hline & $20 \mathrm{q} 13$ & Korn et al., 1999 [71] \\
\hline $18 \mathrm{q}$ & $20 q$ & De Angelis et al., 1999 [72] \\
\hline $\begin{array}{l}\text { 18p21-pter, 15q11-q21, } \\
17 \mathrm{p} 12-13,18 \mathrm{q} 12-21\end{array}$ & $8 \mathrm{q} 23$-ter, 13p14-31, 20q13 & Hermsen et al., 2002 [73] \\
\hline $4,18 p, 14 q$ & $17 \mathrm{p}, 17 \mathrm{q}, 1 \mathrm{q} 11,12 \mathrm{p}, 19$ & Diep et al., 2006 [74] \\
\hline $8 \mathrm{p}, 18 \mathrm{q}, 1 \mathrm{p} 22,4 \mathrm{q} 26,15 \mathrm{q} 21$ & $20,8 \mathrm{q}, 8 \mathrm{q} 28,16 \mathrm{q} 24.3,20 \mathrm{q} 13$ & Camps et al., 2006 [75] \\
\hline $18 \mathrm{q}$ & $13 \mathrm{q}$ & Fensterer et al., 2007 [76] \\
\hline $18,17 \mathrm{p}, \mathrm{Y}, 1 \mathrm{p} 3,8 \mathrm{p}$ & $13,20,7, X, 12,6$ & Muleris et al., 2008 [77] \\
\hline $8 \mathrm{p}, 18,18 \mathrm{q}$ & $3,3 q, 5,5 p, 5 q, 7,8 q, 20,20 q, 13, X$ & Knutsen et al., 2010 [78] \\
\hline $\begin{array}{l}4,5,8,10,14,15,17,18 \\
21,22, \mathrm{Y}, 18 \mathrm{q} 10[\mathrm{i}(8) \\
(\mathrm{q} 10)], 17 \mathrm{q} 10[\mathrm{i}(17)(\mathrm{q} 10)]\end{array}$ & $7,13,20, \mathrm{X}$ & Mitelman Database online \\
\hline
\end{tabular}

defined and thus not mutually exclusive, it is believed that a tumor can occasionally show features of multiple pathways, although the extent and nature of this overlap remains to be determined [77, 81].

CIN is the most common type of genomic instability observed in colon cancer and occurs in $80 \%-85 \%$ of colorectal tumors [82]. It occurs mainly in non-MIN cancers (or MSS for "microsatellite stable") which are proficient for mismatch repair.

CIN CRC show several forms of genomic instability, characterized mainly by chromosomal rearrangements and numerical abnormalities at a greatly increased rate compared with normal cells [83].

Originally, the CIN phenotype was used to describe tumors with a high degree of intercellular heterogeneity in chromosome number, ascertained by counts for a restricted set of chromosome-specific centromeres [79]. CIN was further employed to describe cancers with either aneuploid or polyploid DNA content as measured by cytometry or cytogenetics, or multiple gains or deletions of chromosomes or chromosome arms, or frequent losses of heterozygosity (LOH) [79]. The first cytogenetic observations on cancer cells from colorectal adenocarcinomas were described by Dutrillaux [69]. With classical cytogenetic approach he observed two distinct patterns of chromosomal anomalies. The first one, called "monosomic type", was characterized by many chromosomes losses, including the losses or deletions of chromosomes 18, 17 (short arm = p), 1p, 4, 14, 5 (long $\operatorname{arm}=\mathrm{q}$ ) and 21 . He noticed that this condition frequently evolves towards polyploidy, by duplication of all remaining chromosomes. The second pattern, called "trisomic type", was characterised by the gain of several chromosomes: 7, 12, $\mathrm{X}, 5$ and 8 . The chromosomal anomalies observed seemed at that time to have no topological relationships with oncogenes [69]. Indeed subsequently it became clearer that the cancerspecific aneuploidies generate complex, malignant phenotypes, through the abnormal dosages of the thousands of genes [84].
In general, genomic copy number changes are frequently found in different types of cancer and are believed to contribute to their development and progression through inactivation of tumour suppressor genes, activation of oncogenes, or more subtlly through gene dosage changes [76]. Chromosomal instability is an efficient mechanism for causing the physical loss of a wild-type copy of a tumorsuppressor gene, such as in CRC: APC, TP53, and SMAD family member 4 (SMAD4), whose normal activities oppose the malignant phenotype [85]. The first cytogenetic studies on primary CRC tumors suffered by limitations due to the poor quality of the preparations. The improvement of molecular cytogenetic studies, performed subsequently with the application of fluorescence in situ hybridization (FISH) based techniques such as comparative genomic hybridization $(\mathrm{CGH})$ and spectral karyotyping (SKY), allowed many groups to show that colorectal carcinomas are characterized by multiple patterns of chromosomal imbalances which sequentially accumulate during adenoma to carcinoma progression [73].

Among the first findings, Fearon et al. [70] confirmed a frequent genomic loss in CRC at chromosome 18q21. By using comparative genomic hybridization (CGH) Korn et al. [71] found that most frequent gains are at 20q13 and with the same technique De Angelis et al. [72] determined that gains of $20 \mathrm{q}$ and losses of $18 \mathrm{q}$ were the most frequent aberrations.

Accumulation of losses in 8p21-pter, 15q11-q21, 17p1213 , and $18 \mathrm{q} 12-21$, and gains in 8q23-qter, $13 \mathrm{q} 14-31$, and $20 \mathrm{q} 13$ were found strongly associated with adenoma-tocarcinoma progression, independent of the degree of dysplasia [73].

Diep et al. [74] by applying different statistical analyses and combining these on a large series of genome profiles from reported CRC, were able to identify specific chromosomal alterations linked to the different stages of tumor progression. They found that losses at $17 \mathrm{p}$ and 18 and gains of $8 \mathrm{q}, 13 \mathrm{q}$, and 20 occur early in the establishment of primary CRC whereas loss of $4 \mathrm{p}$ is associated with the 
transition from Dukes' A to B-D stages. They observed that deletion of genes located at chromosome 4 might therefore contribute to increased aggressiveness of the tumor, enabling it to penetrate the muscular layer, and contribute to the establishment of advanced stages; moreover loss of chromosome 4 has been shown to be associated with poor clinical outcome in a large series of CRC [74]. The transition from primary tumor to liver metastasis results correlated with the deletion of $8 p$ and gains of $7 p$ and $17 q$, whereas losses of $14 \mathrm{q}$ and gains of $1 \mathrm{q}, 11,12 \mathrm{p}$, and 19 are late events.

In a pilot study by Fensterer and coworkers [76] using macrodissected paraffin-embedded tissue samples, matrixCGH was performed. The majority of advanced tumours displayed 13q-gain and 18q-loss. In locally restricted tumours, only half tumours showed a gain on $13 \mathrm{q}$ and $7 / 12$ tumours showed a loss on 18q. Interphase-FISH and high-resolution arraymapping of the gain on $13 \mathrm{q}$ confirmed the validity of the arraydata and narrowed the chromosomal interval containing potential oncogenes. The amplification on 13q appeared to harbour candidate genes that might confer a more aggressive phenotype to colorectal cancer cells [76].

Finally, to summarize the numerous investigations performed in the last decade in primary colon cancer tumors, including the recent study by Knutsen and co-workers, comparing the $\mathrm{CGH}$ patterns in all of these reports, gains were most frequent for $3 / 3 q, 5 / 5 p / 5 q, 7,8 q, 20 / 20 q, 13$, and the $\mathrm{X}$, and losses were most frequent for $8 \mathrm{p}$ and 18/18q [78]. Searching for the most frequent structural and numerical aberrations found in the large intestine adenocarcinoma specimens in the Mitelman Database of Chromosome Aberrations in Cancer (http://cgap.nci.nih.gov/ Chromosomes/Mitelman), among unbalanced Chromosomal Abnormalities there are $8 \mathrm{q} 10 \mathrm{i}(8)(\mathrm{q} 10)$ and $17 \mathrm{q} 10$ $\mathrm{i}(17)$ (q10); among numerical trisomies $+7,+13,+20$, and $+\mathrm{X}$; among monosomies $-4,-5,-8,-10,-14,-15,-17$, $-18,-21,-22$, and $-\mathrm{Y}$. The most recurrent aberration found in all cytogenetic studies performed, either in primary tumors or in colon cancer cell lines or in fixed colorectal cancer tissue blocks is thus $18 \mathrm{q}$ (Table 3 ). $\mathrm{LOH}$ of this region indicates an unfavorable outcome in patients with stage II CRC [86]. In the 18q21-18q21.1 region several tumor suppressor genes have been mapped, including SMAD4/DPC4. However, since microsatellite instability was inversely correlated with loss of heterozygosity for chromosomes $5 \mathrm{q}, 17 \mathrm{p}$, and $18 \mathrm{q}$, it has been hypothesized that some colorectal cancers (MSI in particular) may arise through a mechanism that does not necessarily involve loss of heterozygosity [87].

3.1. Mechanisms Responsible of Chromosome Instability in $C R C$. In these last years, there has been intense interest in identifying the mechanisms responsible for the CIN. In most carcinomas, including CRC, chromosomal instability proceeds through two major mechanisms, missegregation that results in aneuploidy through the gain or loss of wholechromosomes, and unbalanced structural rearrangements (unbalanced translocations, deletions, isochromosomes, ...) that lead to the loss and/or gain of chromosomal regions [77]. Lengauer and co-workers [79] showed first that CRC tumors without MIN exhibit a striking defect in chromosome segregation, resulting in gain, or losses in excess of $10^{-2}$ per chromosome per generation. They performed cell fusion experiments between CIN and non-CIN cells (transfected HT-29 cells) and showed that the CIN phenotype acts dominantly at the cellular level, suggesting that it can arise from gain-of-function mutations; aneuploidy was considered indeed the result of an abnormally high rate of CIN [79].

Muleris et al. [77] performed a study to address the question if CIN occurs mainly as the consequence of either missegregation of normal chromosomes (MSG) or structural rearrangement (SR) by karyotyping a consecutive series of 96 near-diploid colorectal cancers. MSGs and SRs were found not randomly associated within tumors, delineating two major pathways of chromosome alterations that consisted of either chromosome gains by MSG or chromosomal losses by both MSG and SR [77].

Recently Knutsen et al. [78] reviewed the karyotypes of 345 cases of adenocarcinoma of the large intestine listed in the Mitelman Database of Chromosome Aberrations in Cancer and compared them with the types of abnormalities observed in 15 established colorectal cancer cell lines, reflecting those seen in primary tumors, using spectral karyotyping (SKY), fluorescence in situ hybridization, and comparative genomic hybridization (CGH). They found that there were no recurrent translocations in either tumors or cell lines; isochromosomes were the most common recurrent abnormalities; and breakpoints occurred most frequently at the centromeric/pericentromeric and telomere regions. They concluded that copy number alterations appear to be the major mechanism for transcriptional deregulation of cancer genes in CRC [78].

Other research groups performed studies addressed to identify proteins that regulate the fidelity of chromosomes (regulation of DNA fidelity during DNA replication and in response to genotoxic stress) either by means of model organisms, such as yeasts, Drosophila and mice. Chromosomal instability is considered the result of somatic mutations in genes that regulate the mitotic spindle checkpoint, DNA replication checkpoints, DNA damage checkpoints, chromosome metabolism, and centrosome function $[81,82]$. In particular, studies were concentrated on three functional pathways: defects in proteins that are involved in doublestrand break repair, kinetochore function, and chromatid segregation [88]. Within this context, Pino and Chung [81] observed that although over 100 genes can cause chromosomal instability in the yeast Saccharomyces cerevisiae, only a few of them have been observed in human tumors. Genes such as hMAD, hBUB1, hBUBR1, hZw10, hZwilch, hRod, $C E N P-A, C E N P-H$, and $A P C$ are involved in the mitotic checkpoint that allows a proper chromosome separation. Mutations of these genes have been found in human cancers, for example mutated $h M A D 1$ and $h M A D 2$ have been found in leukaemia and breast cancer, mutations of $h Z w 10$, $h Z$ wilch, and $h R o d$ have been found in CRC, and mutations of $h B U B 1$ and $h B U B R 1$ resulted in no checkpoint arrest in cancer cell lines [81]. The role of APC in CRC pathogenesis has been largely described in Section 2.1.1. The APC gene 
product is involved in the Wingless/Wnt signal pathway and has a role even in chromosome segregation. Other categories of genes that might contribute to the CIN phenotype in CRC tissues are those involved in centrosome function and duplication, such as those encoding the protein kinase Aurora A (AURKA) and the serine/threonine kinase Plk1 (PLK1), and those involved in the DNA damage response machinery, particularly TP53 [81]. Diep and co-workers (see previous paragraph) supplemented their findings aimed at the identification of chromosomal aberrations that differentiate among the Dukes' stages of colorectal cancer as well as those that are responsible for the progression into liver metastases, with a list of potential target genes for the specific alterations from a publicly available microarray expression dataset of CRC [74]. For instance a gene that shows reduced expression in colorectal carcinomas is CENT1, located at $18 \mathrm{p} 11.32$. The relative protein, a member of the calciumbinding EF-hand protein super-family, has an important role in the determination of centrosome position and segregation, and in the process of microtubule severing. One of the early changes is gain of 20q; the expression data revealed a potential candidate gene for this chromosomal alteration $M Y B L 2$, located at 20q13.12 and directly regulated by the $C D K N 2 A / C C N D / R B / E 2 F$ pathway along with many critical S-phase genes; increased expression of this gene has been observed in several tumors [74]. The expression dataset revealed moreover that IGFBP1 as a gene that may be one of the targets for gain of $7 \mathrm{p}$. IGFBP1, an insulin like growth factor-binding protein, has been observed to have an effect on cell growth, and increased expression of this gene has been seen in different cancer types [74].

Barber et al. [89], through bioinformatic approaches compared 102 human genes highly related to 96 yeast CIN genes and showed that downregulation or genetic disruption of genes directly involved in sister chromatid cohesion (such as MRE11A and CDC4) play a major role in the CIN phenotype in human colorectal tumors [89].

The comparison of array-CGH and gene expression microarray data for primary CRCs and CRC cell lines showed that MSI-associated gene expression changes broadly reflect systematic DNA copy-number differences between MSI tumors, which tend to be near-diploid, and MSS tumors, which tend to be aneuploid [90]. These data demonstrate that DNA copy number changes in cancer cells have profound effects on gene expression, and therefore, this mechanism contributes to the clinical differences between MSI and MSS tumors.

Either TP53 or K-RAS mutations are involved in CRC progression and, given their respective functions (see Section 2.3), both genes could contribute to CIN [81]. According to Pino and Chung [81] other factors that could drive CIN in CRC are telomere dysfunction and loss of heterozygosity (LOH) for the genes on 18q.

3.2. Cytogenetic Aberrations in CRC as Biomarkers. In general cytogenetic aberrations found in cancers are considered biomarkers for disease since they can provide diagnostic, prognostic, and treatment-related information for the associated cancers. However in CRC molecular biomarkers instead of cytogenetic ones are more studied and standardized, compared to other cancers. For example, germline mutations in tumor-suppressor genes, such as $A P C$, $M L H 1$, and $M S H 2$, indicate a very high risk of colorectal cancer and guide the frequency of CRC surveillance and recommendations for prophylactic surgery [85] (see also the previous Section 2.1).

A few genomic markers are useful for prognosis. Microsatellite instability and loss of heterozygosity at chromosome $18 \mathrm{q}$ are the two best-defined molecular prognostic markers [91].

Studies have been performed to understand functional relevance of chromosomal aberrations for colorectal cancer progression but these somatic markers have modest or unconfirmed prognostic value and are not currently used to direct care. Patients with MSI sporadic colorectal cancers generally have a favorable prognosis [91]; poor survival in stage II and III colon cancers is associated with the loss of p27 (a proapoptotic regulator of the cell cycle) or the loss of heterozygosity at chromosomal location 18q [78, Makowitz et al., 2009]. However in a large prospective study of patients with non-MSI-high colorectal cancer, 18q LOH or allelic imbalance was not associated with patient survival [92].

Mutations in K-RAS, observed in approximately $40 \%$ of colon tumours, have significant implications for predicting likelihood of response to the antibody-based EGFR inhibitors (cetuximab and panitumumab) therapy, with $K$ RAS mutant patients now clearly shown to be inherently resistant to these agents [1].

\section{Epigenetics and Colorectal Cancer}

Epigenetics is defined as heritable changes in gene expression that are not accompanied by changes in DNA sequence. An epigenetic modification is DNA methylation, a covalent addition of a methyl group $(\mathrm{CH} 3)$ to the nucleotide cytosine. In mammals, most of the DNA CpG sites are methylated (90\%-98\%), but there are specific CpG-rich areas of DNA where most $\mathrm{CpGs}$ are not methylated (CpG islands); a few genes are imprinted genes, regulated by methylation of the CpG islands in their promoter, and the markings are stably replicated during cell division but are reversed when inherited through an individual of the opposite sex. Promoter hypomethylation has been associated with an increased gene transcription. DNA hypermethylation occurs at specific regulatory sites in the promoter regions or repetitive sequences. A heavy density of cytosine methylation in the $\mathrm{CpG}$ islands of the tumor suppressor gene promoters can lead to a complete block of transcription, and many types of cancer use this mechanism to inactivate tumor suppressor genes. Epigenetic events are a characteristic of human cancer, including CRC. Other epigenetic modifications include histone acetylation and gene silencing mediated by small noncoding RNA (microRNA or miRNA). Table 4 shows epigenetic alterations observed in CRC.

4.1. DNA Methylation in CRC. Methylation of CDKN2A, a tumour suppressor gene, is detected in $40 \%$ of colorectal 
TABLE 4: Epigenetic alterations in colorectal cancer.

\begin{tabular}{lll}
\hline & Genes involved in CRC & Gene functions and epigenetic changes \\
\hline APC & Adenomatosis polyposis coli & Tumour suppressor gene, antagonist of Wnt signaling pathway. \\
MGMT & $\begin{array}{l}\text { O-6-methylguanine-DNA } \\
\text { methyltransferase }\end{array}$ & $\begin{array}{l}\text { Involved in repairing DNA damage; silencing by hypermethylation correlates with } \\
\text { G to A mutations in the K-RAS oncogene. }\end{array}$ \\
CDKN2A/P14 & $\begin{array}{l}\text { Cyclin-dependent kinase inhibitor } 2 \mathrm{~A}, \\
\text { alternated reading frame }\end{array}$ & $\begin{array}{l}\text { Tumour suppressor gene, involved in cell cycle regulation; its silencing by } \\
\text { hypermethylation is associated with increased risk of CRC. }\end{array}$ \\
HLTF & Helicase-like transcription factor & $\begin{array}{l}\text { This gene encodes for a chromatin remodelling factor. Members of this family have } \\
\text { helicase and ATPase activities and are thought to regulate transcription of certain } \\
\text { genes by altering the chromatin structure around those genes. Its silencing could } \\
\text { increase CRC risk. }\end{array}$
\end{tabular}

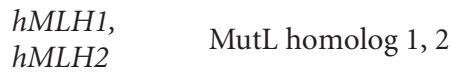

DNA repair genes; their silencing, by hypermethylation is associated with MSI CRC.

Tumor suppressor gene that plays an important role in regulating the cell cycle;

CDKN2A/P16 Cyclin-dependent kinase inhibitor 2A mutations or inactivation by hypermethylation in the CDKN2A gene are associated with increased risk of a wide range of cancers.

CDH13 H-cadherin

UNC5C Unc-5 homolog C

DCC Deleted in colorectal carcinoma

It is a regulator of cellular adhesion-deadhesion processes, and its inactivation through hypermethylation contributes to the dissemination of cancer cells.

UNC5C is one of the Netrin-1 receptors, has tumor-suppressor activity. The loss of UNC5C expression is particularly prominent in colorectal cancer.

Encodes for a membrane-bound protein of the immunoglobulin-CAM family and may function as tumor suppressor gene which controls programmed cell death. DCC has been identified on a region of chromosome 18, which is deleted in $70 \%$ of colorectal cancer.

COX2 Prostaglandineendoperoxide synthase 2

Involved in inflammation and mitogenesis, tumour angiogenesis and metastasis.

HACE $1 \quad$ E3 ubiquitin ligase

RASSF1A Ras association (RalGDS/AF-6) domain family 1

HACE1 might act as a tumor suppressor in colorectal carcinomas and HACE1 methylation might present a malignant potential in colorectal cancer.

Suppressor protein involved in death receptor-dependent apoptosis and it is localized to microtubules.

This gene encodes a member of the runt domain-containing family of transcription factors and can either activate or suppress transcription. It also interacts with other transcription factors. It functions as a tumor suppressor, and its silencing by hypermethylation could influence CRC risk.

SOCS1 is involved in negative regulation of cytokines that signal through the JAK/STAT3 pathway; its silencing by hypermethylation could influence CRC risk.

SOCS1 Suppressor of cytokine signaling 1

CHFR functions as part of an early G2/M checkpoint. CHFR might act as a tumor Checkpoint with FHA and RING finger suppressor and CHFR methylation might, therefore, be a particular phenomenon of early colorectal cancer.

Members of this family are membrane-anchored proteins and have been implicated in a variety of biological processes involving cell-cell and cell-matrix interactions.

A disintegrin and metalloproteinase domain 23 ADAM23 may be downregulated by aberrant promoter hypermethylation during the progression of colorectal cancer.

May act as a tumor suppressor by inhibiting cell proliferation and its silencing by hypermethylation correlates with CRC risk.

Deleted in lung and oesophageal cancer 1

SERF1 Secreted frizzled -related protein 1

Epigenetic silencing of SFRP genes lead to aberrant activation of the Wnt pathway.

MYOD Myogenic factor 3

MyoD removes cells from the cell cycle (halt proliferation) by enhancing the transcription of p21. Its silencing could influence CRC risk.

TIS gene is a tumor suppressor, which encodes a cyclin-dependent kinase inhibitor and it is positively regulated by transforming growth factor- (TGF-). 
TABle 4: Continued.

\begin{tabular}{|c|c|c|}
\hline \multicolumn{2}{|c|}{ Genes involved in CRC } & \multirow{2}{*}{$\begin{array}{l}\text { Gene functions and epigenetic changes } \\
\text { P73 maps to chromosome region } 1 \text { p } 36.3 \text {, which is frequently deleted in a variety of } \\
\text { solid tumors. Participates in the apoptotic response to DNA damage. May be a } \\
\text { tumor suppressor protein, so its silencing by aberrant methylation correlates with } \\
\text { CRC risk. }\end{array}$} \\
\hline P73 & Tumor protein p73 & \\
\hline WT1 & Wilms tumor 1 & $\begin{array}{l}\text { It has a tumor suppressor as well as an oncogenic role in tumor formation. Then } \\
\text { aberrant methylation could influence CRC risk. }\end{array}$ \\
\hline Cyclin A1 & Cyclin A1 & $\begin{array}{l}\text { Binds to trascription factor E2F-1, p21, Rb family protein; aberrant methylation in } \\
\text { this gene could influence CRC risk. }\end{array}$ \\
\hline MINT & & $\begin{array}{l}\text { Probably represses transcription via the recruitment of large complexes containing } \\
\text { histone deacetylase proteins. May bind both to DNA and RNA. }\end{array}$ \\
\hline$R A R-b$ & Retinoic acid receptor beta & $\begin{array}{l}\text { Tumor suppressor gene, mediates the growth inhibitory action of retinoic acid; its } \\
\text { silencing by hypermethylation promotes tumour progression. }\end{array}$ \\
\hline $\mathrm{CDH} 5$ & $\begin{array}{l}\text { Chromodomain helicase } \\
\text { DNA-binding protein } 5\end{array}$ & $\begin{array}{l}\text { Tumor suppressor gene involved in regulating chromatin architecture and in } \\
\text { modifying chromatin structure in an ATP-dependent manner. }\end{array}$ \\
\hline$R G C-32$ & Response gene to complement & $\begin{array}{l}\text { RGC-32 regulate a group of genes involved in chromatin assembly. RGC-32 } \\
\text { knockdown induced an increase in acetylation of histones H2B lysine } 5 \text { (H2BK5), } \\
\mathrm{H} 2 \mathrm{BK} 15, \mathrm{H} 3 \mathrm{~K} 9, \mathrm{H} 3 \mathrm{~K} 18 \text {, and } \mathrm{H} 4 \mathrm{~K} 8 \text {, a decreased expression of SIRT1 and } \\
\text { trimethylation of histone } \mathrm{H} 3 \mathrm{~K} 27 \text {. RGC-32 silencing is associated with chromatin } \\
\text { remodeling and activation of cell cycle. }\end{array}$ \\
\hline miRNA124a & & $\begin{array}{l}\text { It could be repressed by CpG island hypermethylation, relative to normal tissue; it } \\
\text { could so influence expression of oncogenic protein. }\end{array}$ \\
\hline $\begin{array}{l}\operatorname{miR}-34 b / c \\
m i R-9-1 \\
\operatorname{miR}-129-2 \text { and } \\
R-137\end{array}$ & & $\begin{array}{l}\text { Methylation of these genes was observed in CRC cell lines and in primary CRC } \\
\text { tumour respect to normal mucosa. }\end{array}$ \\
\hline$m i R-21$ & & $\begin{array}{l}\text { Alterated methylation could upregulate this microRNA in colorectal cancer, } \\
\text { promoting invasion and metastasis. }\end{array}$ \\
\hline $\operatorname{miR}-143$ & & $\begin{array}{l}\text { Down regulated in colon cancer; expression of K-RAS was found inversely } \\
\text { correlated with this microRNA in vivo; miR-143 was inversely correlated with } \\
\text { mRNA and the protein expression of DNMT3A in CRC. }\end{array}$ \\
\hline $\operatorname{miR} 135$ & & $\begin{array}{l}\text { Inversed association between this microRNA and the level of APC mRNA was } \\
\text { observed in colorectal adenomas and carcinoma. }\end{array}$ \\
\hline$m i R-34 a$ & & $\begin{array}{l}\text { miR-34a may act as a tumor suppressor by blocking SIRT1, thereby permitting } \\
\text { increased p } 53 \text { activity. By deacetylating p } 53 \text {, SIRT1 decreases the ability of p53 to } \\
\text { promote cell cycle arrest. SIRT1 activity may increase the risk of cancer. MiR 34a } \\
\text { silencing, by hypermethylation cannot inhibit SIRT1 activity. }\end{array}$ \\
\hline
\end{tabular}

cancers and has been found also in colorectal adenoma. Methylation of P16 was found in colorectal cancer (Dukes stage C) suggesting that P16 inactivation was important for tumorigenesis [93]. Also, Wettergren and co-workers found an increase of P16 methylation in older than younger patients; moreover the frequency of P16 hypermethylation was highest in right-sided colon followed by rectum and leftsided colon. Furthermore patients without methylation of P16 in mucosa, survived more than patients with hypermethylation [94]. Keyes and coworkers [95] found that aging causes DNA bypomethylation, but increases $p 16$ promoter methylation in mouse colons and the effect is dependant on dietary folate.

A different CDH13 methylation between poorly differentiated colorectal cancer and differentiated cancer was found.
A significant increase of HACE1 gene methylation in colorectal cancer was observed in the maximal tumour size. A significant alteration of UNC5C methylation in colorectal cancer, principally in Dukes stage $\mathrm{C}$ than in earlier stages was also observed [93]. Wasson and coworkers [96] demonstrated that in folate depleted colon cells, there was an increment of global DNA hypomethylation; particularly there was a major hypomethylation in the region of TP53 gene. DNA hypomethylation is important for genome stability; then it may cause strand breaks and mutagenesis through alterations in chromatin conformation, which increase the accessibility of the DNA to DNA-damaging agents promoting genomic instability.

The activation of proto-oncogenes, such as RAS gene and the inactivation of tumoursuppressor genes, such as the 
APC and TP53 have been identified in colorectal cancer. The loss of UNC5C and DCC (deleted in colon cancer) expression is associated with their methylation [97, 98]; aberrant methylation of these genes was detected in $68 \%$ and $56 \%$ respectively of the primary colorectal carcinomas. Hibi and Nakao [99] studied the combined methylation status of P16, P14, HLFT (helicase-like transcription factor), SOCS1 (suppressor of cytokine signalling-1), CDH13 (Hcadherin), RUNX3 (a member of the human runt-related transcription factor family) and CHFR (checkpoint with FHA and RING finger) in 58 primary colorectal carcinomas and correlated them with the pathologic features of the patients. They found a significant difference in histology between the number of methylated genes and the colon cancer stadia. Then the methylated status of colorectal carcinomas was significantly correlated with malignant potential. In a study of Ramírez et al. [100], 47\% of normal samples (82 individuals) had nonmethylated gene and $41 \%$ of these had one or two methylated-loci. Three or more methylatedloci were observed in $12 \%$ of normal colon tissues. In contrast, three or more methylated loci were observed in $33 \%$ of tumors samples. MGMT and P14 were the most frequent methylated genes in CRC lesions and the least commonly methylated in the corresponding nontumour tissue; the $h M L H 1$ gene, instead, was the least frequent methylated gene in CRC tissues. Choi and co-workers observed that the promoter region of the ADAM23 gene was hypermethylated in colorectal cancer cell lines and tissues. Gene silencing caused by aberrant promoter hypermethylation is likely to result in abnormal cell-cell interactions and favour cell migration and metastasis [101]. DLEC1, located at $3 \mathrm{p} 22.3$, is a common tumour suppressor locus with frequent genetic abnormalities in multiple cancers. It was found frequently silenced by promoter methylation in colorectal and gastric cancers in a tumour-specific manner. Tumour-specific promoter methylation makes this gene a biomarker for tumour early diagnosis. Reintroduction of DLEC1 into silenced tumour cells significantly suppressed tumour cell clonogenicity [102]. Germline mutations in the tumour suppressor APC cause FAP, and somatic mutations are common in sporadic CRCs. Hypermethylation of APC promoter 1A has been reported in early steps of carcinogenesis in several tumours [103]. A study reported that the frequencies of aberrant promoter methylation were $16 \%$ for $C D H 1,2 \%$ for $P 16,4 \%$ for $M G M T$ and $24 \%$ for APC genes. An aberrant methylation of at least one of these genes was found in 45 of $51(88 \%)$ primary tumors [104]. Ras association domain family protein 1A (RASSF1A) is a tumor suppressor protein involved in death receptordependent apoptosis and it is localized to microtubules. RASSF1A methylation levels were found significantly higher in distal CRCs; then methylation levels of RASSF1A and SFRP1 in the normal-appearing mucosa of distal CRC cases were significantly higher than those in the proximal CRC cases. Hypermethylation of these genes was also positively correlated with age [105]. Silencing of SFRP by promoter methylation causes constitutive activation of the Wnt/Bcatenin signaling patway, which is associated with several tumors as well as CRC. Thus changes in methylation pattern of the promoter $\mathrm{CpG}$ islands are very common in CRC. In a study 31 targets have been analyzed, 65 cases of CRC, 8 cases of adenoma, five cases of noncancerous mucosa from the cancer patients and one case mucosa from the non-cancerous patient. By taking the methylation profile of the mucosa from the non-cancerous patient as the reference, the following genes MGMT, hMLH1, P16, MINT1, MINT31, COX2, cyclin A1, CDX1, RAR-b, MYOD1, P15, CDH13, CXX1, P73, and WT1 assumed altered methylation patterns [106].

4.2. Modifications of Histones in Colorectal Cancer. Another epigenetic change is chromatin modification, specifically, covalent modifications of the histone proteins. Histone acetylation is a hallmark of active regions while hypoacetylated histone tails are found in transcriptionally inactive euchromatic or heterochromatic regions. The acetylation/deacetylation is performed by histone deacetylases (HDACs) and histone acetyl transferases. Phosphorylation of serine 10 in histone $\mathrm{H} 3$ has been correlated with gene inactivation in mammalian cells; methylation of lysine 9 of histone $\mathrm{H} 3$ is associated with DNA silencing. The modifications present on histone tails are recognized by chromatin-remodelling enzymes that are able to modify chromatin structure; chromodomain helicase DNA-binding protein 5 (CDH5) is a tumor suppressor that is involved in proliferation, apoptosis, and senescence. It was found that epigenetic inactivation of $\mathrm{CDH} 5$ contributes to aberrant structural changes of chromatin on genome of the cancer cells (colon, breast, cervix, glioma) [107].

Mazón Peláez and coworkers suggest that histone covalent modifications can be affected by oncogenic RAS pathways to regulate the expression of target genes like Cyclin D1 or E-cadherin and that the dynamic balance of opposing histone-modifying enzymes is critical for the regulation of cell proliferation [108].

Response gene to complement 32 (RGC-32) is a substrate and regulator of $\mathrm{CDC} 2$, and its overexpression induces cell cycle activation. The expression of $R G C-32$ was found higher in advanced stages of colon cancer than in precancerous states or the initial stages of colon cancer. RGC-32 knockdown induced an increase in acetylation of histones $\mathrm{H} 2 \mathrm{~B}$ lysine 5 (H2BK5), H2BK15, H3K9, H3K18, and H4K8. RGC32 silencing was also associated with decreased expression of SIRT1 and decreased trimethylation of histone H3K27. These data suggest that RGC-32 may contribute to the development of colon cancer by regulating chromatin assembly [109].

4.3. MiRNA and Colorectal Cancer. Another type of epigenetic event is driven by microRNAs (miRNAs), short, non-coding RNAs, that regulate the translation of several genes binding to their $3^{\prime}$ UTR regions (degrading mRNA or repressing the expression of their proteins). MiRNAs are involved in several biological processes; a study marked a miR-34a decrease in human colon cancer tissues compared with normal tissues; miR-34a inhibited SIRT1 expression and increased the level of acetylated p53; suppression of SIRT1 by miR-34a led to apoptosis in human colon cancer cells [110]. Methylation of miR-34b/c, miR-9-1, miR-129-2 and R-137 
genes was observed in CRC cell lines and in primary CRC tumour in respect to normal mucosa. Expression of $K$-RAS was found inversely correlated with miR143 in vivo; miR143 was inversely correlated with mRNA and the protein expression of DNMT3A in CRC. Then, miRNAs expression could be reduced by means of DNA methylation, but also it could downregulate expression of DNMT and influence the expression of tumour suppressor genes. Inverse association between the level of APC mRNA and miR135 was observed in colorectal adenomas and carcinomas [111]. In colorectal tumors miR-124a could be repressed by CpG island hypermethylation, in respect to normal tissues; it could thus influence the expression of oncogenic proteins which are not normally regulated by methylation. MiRNA, as miR-29, could also target DNMT $3 \mathrm{~A}$ or $3 \mathrm{~B}$, participating to reduction of DNA methylation. MiRNAs could be downregulated in tumors, due to chromosomal mutations, normally present in cancers. Recent studies have observed a role of miRNA in metastasis formation. MiR-21, upregulated in colorectal cancer, promotes invasion and metastasis by down regulating $\operatorname{Pdcd} 4$ [112].

\subsection{Genetic and Environmental Factors Likely Affecting DNA Methylation in Colorectal Cancer}

4.4.1. Polymorphisms of Folate Metabolizing Genes and DNA Methylation in Colorectal Cancer. Folate is a fundamental nutrient mainly required for either DNA synthesis or methylation processes. Particularly, it is required for the synthesis of S-adenosylmethionine (SAM) the major intracellular methyl donor. The availability of SAM is directly influenced by the diet. SAM is formed from methyl groups derived from choline, methionine, or methyltetrahydrofolate (MTHF). Because of their involvement in DNA methylation, single nucleotide polymorphisms (SNPs) in genes involved in folate metabolism could be associated with either aberrant gene methylation or CIMP. Indeed, several polymorphisms of genes involved in folate metabolism, including methylenetetrahydrofolate reductase (MTHFR) C677T and A1298C, methionine synthase (MTR) A2756G and methionine synthase reductase (MTRR) A66G; thymidylate synthase (TYMS) 28 bp repeats, DNA methyltransferase (DNMT3b) -149C > T, and the transcobalamin II (TCNII) 776G variant, often in combination with folate intake, have been associated with CRC risk, CIMP, MSI phenotypes, and aberrant methylation of CRC genes (Table 5) [113-122].

4.4.2. Environmental Factors that Might Influence Epigenetic Patterns in Colorectal Cancer. Studies where people migrate from low to high CRC risk areas of the world, demonstrate that changes of diet and physical activity enhance the incidence of cancer in a high-risk country even over one or two generations [123]. Moreover, monozygotic twins carriers of high penetrant genetic alteration in HNPCC, associated with MLH1 mutations, develop cancer at different ages. These observations suggest a role of the environment in epigenetic changes [124]. Table 5 summarizes the contribution of environmental factors to epigenetic modifications relevant to CRC.
Low levels of folate in the diet or in blood were associated with higher CRC risk; inversely high intake of folate has been associated with reduced CRC risk [125]. It also observed that high plasma folate levels may be associated with increased CRC risk [126]. A study observed a small trend for higher levels of serum folate in the group of patients with methylated tumours, compared to those with unmethylated tumours $(P=.06)$; moreover it was observed a trend for association between serum folate/vitamin B12 levels and gene promoter methylation: higher serum folate/vitamin B12 levels were strongly associated with promoter methylation of $P 16$ and had an association (trend) with promoter methylation of MLH1 and MLH2 genes [127]. Other studies demonstrated that high folate intake enhances colorectal recurrence and progression. Animal studies demonstrated that high-dose of folic acid might promote colorectal tumorigenesis $[128,129]$. Folate supplementation could protect against CRC in normal colorectal tissue, instead it could promote tumour progression in pre-existing lesions [125].

Alterations in folate metabolizing genes or deficiency of folate can result in elevated homocysteine levels. Folate deficiency is significantly more associated with oncogenesis when combined with hyper-omocysteinemia (increased risk of 17 times of carcinogenic lesions); moreover, inflammatory bowel disease patients with folate deficiency and hyperhomocysteinemia might be associated with increased risk colorectal cancer [130]. It was observed that a positive association between vitamin B6 and rectal cancer risk exists in women. Among men, methionine was associated with a decreased risk of proximal colon cancer whilst among women it was inversely associated with rectal cancer [131].

Choline could derive from the diet, but also from de novo biosynthesis by means of an enzyme coded by the gene phosphatidylethanolamine-N-methyltransferase $(P E M T)$. One of choline metabolites, betaine, participates in the methylation of homocysteine to form methionine. Then choline and betaine have been hypothesized to decrease the risk of colorectal cancer. Estrogens cause a marked upregulation in PMET mRNA expression and enzyme activity, then premenopausal women have an enhanced capacity for de novo biosynthesis of choline. In choline deficient cells in culture, and in fetal rodent brains from mothers fed with choline-deficient diets, methylation of the CDKN3 gene promoter decreased, resulting in overexpression of this gene which inhibits cell proliferation. Maternal diet high in choline and/or methionine and/or methyl-folate during pregnancy results in epigenetic changes in gene expression in the fetus [132].

Alcohol consumption was found to be a risk factor for colorectal tumorigenesis. In an in vivo study (male rats), it was observed that a decrease in RFC1 (reduced folate carrier) mRNA and protein expression exists during alcoholism. That is a possible reason of lower blood folate levels commonly found in chronic alcoholics [133]. Alcohol in murine studies appears to reduce MTR levels; then it could induce DNA hypomethylation [134]. In a Dutch study, higher frequency of promoter methylation of APC 1A, P14, MLH1, MGMT, and RASSF1A was observed in low-folate/high-alcohol individuals respect to high-folate/low alcohol consumers [135]. 
TABLe 5: Genetics and environmental factors linked to epigenetic changes in CRC.

\begin{tabular}{|c|c|}
\hline Genetic and environmental factors & Epigenetic changes in CRC \\
\hline TYMS 28 bp 3R/3R genotype & Associated with CIMP-CRC \\
\hline MTHFR 677TT + 1298 CC genotypes/adequate folate intake & Reduced MSI CRC risk \\
\hline $\begin{array}{l}\text { MTHFR AC or CC genotype, low folate and methionine, high } \\
\text { alchol }\end{array}$ & Associated with CIMP+ CRC risk \\
\hline TCNII $776 G$ variant & Reduced CIMP+ CRC risk \\
\hline MTHFR 677CT genotype & Decreased MGMT promoter hypermethylation \\
\hline MTR A2756G & Reduced CIMP CRC risk, among men \\
\hline MTRR A66G & Reduced $M L H 1$ methylation \\
\hline DNMT $-149 T T$ & Reduced risk proximal CRC (principally CIMP+ tumour) \\
\hline High serum folate/vitB12 & $\begin{array}{l}\text { Associated with P16 promoter methylation and with MLH1, MLH2 } \\
\text { promoter methylation(trend) }\end{array}$ \\
\hline Choline deficiency & Reduced CDKN3 promoter methylation \\
\hline Low folate/High alcohol & $\begin{array}{l}\text { Increased APC } 1 A, P 14, M L H 1, M G M T \text {, and RASSF1A promoter } \\
\text { methylation (trend) }\end{array}$ \\
\hline Alchol (murine studies) & Reduced MTR levels/DNA hypomethylation \\
\hline Tobacco & Reduced methylation levels of MGMT, RAR- $b$, and SST genes \\
\hline $\begin{array}{l}\text { Heavy smokers/low folate/low fiber intake/long-term alcohol } \\
\text { consumption }\end{array}$ & Increased CIMP+ CRC risk (trend) \\
\hline Green tea & Demethylation of MLH1, MGMT, and P16 genes \\
\hline Energy restriction & Decreased CIMP+ CRC \\
\hline Higher dietary fiber & Reduced risk CIMP $+\mathrm{CRC/restore} \mathrm{protein} \mathrm{acetylation}(\mathrm{p} 53, \mathrm{Sp} 1, \mathrm{Sp} 3)$ \\
\hline Obesity & Increased CIMP-low CRC, not CIMP high CRC \\
\hline Physical activity/use NSAIDs & Reduced CIMP-low and CIMP-high CRC \\
\hline
\end{tabular}

Tobacco could also influence CRC risk. The methylation levels for MGMT, RAR-b, and SST decrease in the following sequence: nonsmokers without colorectal adenomas $>$ smokers without colorectal adenomas $>$ nonsmokers with colorectal adenomas $>$ smokers with colorectal adenomas. Smoking predisposes to diminished methylation of several genes, which, in turn, contribute to colorectal adenoma development [136]. A study reported, although without statistical significance, that the risk of CIMP-high tumor, among smokers of 20 or more cigarettes per day, was higher among those with low folate and low fiber intake and those who had greater longterm alcohol consumption. Moreover, among women alcohol and cigarette smoking were associated with risk of CIMP-high tumors; women who smoked 20 or more cigarettes per day and consumed little or no alcohol did not have an increased risk of a CIMP-high tumors [137].

In an in vitro study on HT 29 cells, green tea inhibited DNMT1 causing $\mathrm{CpG}$ demethylation and reactivation of previously methylated genes ( $h M L H 1, M G M T, P 16)$. Also selenium suppressed aberrant DNA methylation by means of DNMT inhibition [134].

Energy restriction during adolescence and early adulthood is associated with the CIMP phenotype in CRC, suggesting that exposure to a transient environmental condition during this period of life may result in persistent epigenetic changes that later influence CRC development. Individuals exposed to a period of severe short-term energy restriction, had a decreased risk of developing a CIMP tumor later in life respect to individuals who were not exposed. The prepubertal and pubertal years are a period of rapid growth and hormonal change, where insulin-like growth factor-1 (IGF-1) can be four-times the normal adult serum concentration. IGF- 1 inhibits apoptosis and stimulates proliferation of colonic epithelial cells in vitro. High levels of IGF-1 have been associated with a significant increase in colon cancer risk [138]. It could be possible that energy restriction, during puberty, may permanently influence the growth hormoneIGF axis, subsequently influencing methylation patterns later in life [139].

Fiber intake reduces CRC risk, with dilution of fecal potential carcinogens, promoting a favorable colonic microflora, by adsorption of bile acids and by production of protective short-chain fatty acids (SCFAs principally acetate, propionate, and butyrate) through fermentation by endosymbiotic bacteria. Butyrate is a potent inhibitor of histone deacetylases (HDACs); reduced levels of butyrate will cause alterations in global protein acetylation, which may be permissive for colorectal cancer progression, while elevation of fibre levels and consequent butyrate levels may reduce or reverse these processes and restore a "normal" profile of protein acetylation. Acetyl proteins identified are nuclear structural proteins, transcription factors including p53, Sp1, and Sp3, and structural proteins including tubulin and cytokeratins [140]. Higher dietary fiber was associated with reduced risk of having a CIMP-high tumor [137]. Obese 
individuals were at 2-fold increased risk of CIMP-low colon cancer, but obesity does not influence CIMP-high tumors [137].

DNA methylation has been also hypothesized as being a consequence of inflammation. Prostaglandins, that promote inflammation and fever, are produced within the body cells by the enzyme cyclooxygenase (COX). Nonsteroidal antiinflammatory drugs (NSAIDs) block the COX enzymes and reduce prostaglandins throughout the body, then their assumption has been hypothesized to be associated with development of colon tumors that display CIMP.

Physical activity and use of NSAIDs were inversely associated with both CIMP-low and CIMP-high tumors. The protective effect associated with regular NSAIDs use largely disappeared among heavy smokers [137].

\section{Concluding Remarks}

An unresolved question related to genomic instability, which has been raised in many papers, is whether CIN arises early in tumorigenesis and initiates the adenoma-carcinoma sequence or whether it is acquired during this process and facilitates the formation of colon cancer. According to the genetic model of colorectal tumorigenesis, cancers develop over the course of 20-40 years due to genetic disruption of the APC, RAS, and p53 pathways. Genetic instability arises somewhere during the process of colorectal tumorigenesis, but whether it is the first event and therefore, initiates and drives the neoplastic transformation is still a matter of much debate [141].

Some reports suggest that CIN arises early in colorectal tumorigenesis and, subsequently, drives tumor progression. Michor et al. [141] developed a mathematical representation of the evolutionary dynamics of colorectal tumorigenesis and found that one or two CIN genes in the genome are enough to make sure CIN emerges early.

However this view is not universally accepted: some Authors are inclined to believe that CIN is acquired during tumorigenesis and facilitates progression to malignancy. Even in light of the latest knowledge, the question is still considered unresolved (see the recent review by Pino and Chung [81]).

Different tumors show various patterns of aneuploidy. However, since chromosomal changes found in the tumors of different individuals are not random, aneuploidy should not be considered a side effect. The loss of heterozigosyty that occur in the first phases of the CRC cancerogenesis, as well as the alteration of methylation pattern of multiple key genes can drive the development of colorectal cancer by facilitating the acquisition of multiple tumor-associated mutations and the instability phenotype.

Aberrant CpG island methylation is involved in cancer development, but it is not yet clear if it is a cause or an effect of cancer formation, which genes are methylated during the pathogenesis of individual cancers, when is the time of methylation and gene silencing, how specific methylation profiles are established, and what determines tumor typespecific methylation [103].
A restricted folate diet or SNPs in one-carbon metabolism, then the reduction of the total amounts of DNA methylation in human tumors leads to hypomethylation of repetitive DNA sequences, contributing to the origin of cancer cells by generation of chromosomal instability, reactivation of transposable elements, and loss of imprinting; moreover, hypomethylation could activate proto-oncogenes. The misincorporation of uracil into human DNA, favoured when thymidylate availability is restricted, could also increase the frequency of chromosome cleavage. On the other hand, tumor suppressor genes could gain CpG island methylation, resulting in the inactivation of these protecting proteins. Moreover epigenetic alterations could influence either cancer initiation or progression. A tumor could take different paths; therefore it is important to obtain data about age, sex, tumor site, stadiation, and diet when investigating genetic and epigenetic risk factors for CRC. DNA methylation and histone modification changes are reversible, while genetic mutations are not; then, it could be interesting to evaluate their relationship with dietary factors and the genetic background of the individuals, for the development of novel strategies for cancer prevention.

There is a need for a preventive strategy that can utilize biomarkers in order to stratify patients into appropriate screening or surveillance programs. In CRC, the best biomarkers are germline APC mutations, which are highly predictive of colon cancer. Moreover, CRC in particular has a potential for prevention, since most cancers follow the adenoma-carcinoma sequence, and the interval between detection of an adenoma and its progression to carcinoma is usually about a decade. There is also need of identifying clinical variables (biomarkers) associated with clinical outcomes. New molecular biomarkers may be identified in the next decade, such as epigenetic methylation patterns and genetic polymorphisms.

\section{Acknowledgment}

F. Coppedè was supported by the Istituto Toscano Tumori, Florence, Italy.

\section{References}

[1] D. Cunningham, W. Atkin, H. J. Lenz et al., "Colorectal cancer," The Lancet, vol. 375, no. 9719, pp. 1030-1047, 2010.

[2] R. Labianca, G. D. Beretta, B. Kildani et al., "Colon cancer," Critical Reviews in Oncology/Hematology, vol. 74, no. 2, pp. 106-133, 2010.

[3] K. W. Jasperson, T. M. Tuohy, D. W. Neklason, and R. W. Burt, "Hereditary and familial colon cancer," Gastroenterology, vol. 138, no. 6, pp. 2044-2058, 2010.

[4] B. M. Wolpin and R. J. Mayer, "Systemic treatment of colorectal cancer," Gastroenterology, vol. 134, no. 5, pp. 12961310, 2008.

[5] E. R. Fearon and B. Vogelstein, "A genetic model for colorectal tumorigenesis," Cell, vol. 61, no. 5, pp. 759-767, 1990.

[6] A. Bellacosa, "Genetic hits and mutation rate in colorectal tumorigenesis: versatility of Knudson's theory and 
implications for cancer prevention," Genes Chromosomes and Cancer, vol. 38, no. 4, pp. 382-388, 2003.

[7] L. E. Johns and R. S. Houlston, "A systematic review and meta-analysis of familial colorectal cancer risk," American Journal of Gastroenterology, vol. 96, no. 10, pp. 2992-3003, 2001.

[8] C. A. Gonzalez, E. Riboli, K. Overvad et al., "Diet and cancer prevention: contributions from the European Prospective Investigation into Cancer and Nutrition (EPIC) study," European Journal of Cancer, vol. 46, no. 14, pp. 2555-2562, 2010.

[9] S. Hiraoka, J. Kato, S. Fujiki et al., "The presence of large serrated polyps increases risk for colorectal cancer," Gastroenterology, vol. 139, no. 5, pp. 1503-1510, 2010.

[10] M. Hoffmeister, S. Schmitz, E. Karmrodt et al., "Male sex and smoking have a larger impact on the prevalence of colorectal neoplasia than family history of colorectal cancer," Clinical Gastroenterology and Hepatology, vol. 8, no. 10, pp. 870-876, 2010.

[11] L. Huang, X. Wang, W. Gong, Y. Huang, and B. Jiang, "The comparison of the clinical manifestations and risk factors of colorectal cancer and adenomas: results from a colonoscopybased study in southern Chinese," International Journal of Colorectal Disease, vol. 25, no. 11, pp. 1343-1351, 2010.

[12] S. C. Larsson and A. Wolk, "Meat consumption and risk of colorectal cancer: a meta-analysis of prospective studies," International Journal of Cancer, vol. 119, no. 11, pp. 26572664, 2006.

[13] M. Bretthauer, "Evidence for colorectal cancer screening," Best Practice \& Research Clinical Gastroenterology, vol. 24, no. 4, pp. 417-425, 2010.

[14] C. C. Dahm, R. H. Keogh, E. A. Spencer et al., "Dietary fiber and colorectal cancer risk: a nested case-control study using food diaries," Journal of the National Cancer Institute, vol. 102, no. 9, pp. 614-626, 2010.

[15] J. S. Hildebrand, E. J. Jacobs, P. T. Campbell et al., "Colorectal cancer incidence and postmenopausal hormone use by type, recency, and duration in cancer prevention study II," Cancer Epidemiology Biomarkers and Prevention, vol. 18, no. 11, pp. 2835-2841, 2009.

[16] D.-H. Kim, S. A. Smith-Warner, D. Spiegelman et al., "Pooled analyses of 13 prospective cohort studies on folate intake and colon cancer," Cancer Causes and Control, vol. 21, no. 11, pp. 1919-1930, 2010.

[17] E. Half, D. Bercovich, and P. Rozen, "Familial adenomatous polyposis," Orphanet Journal of Rare Diseases, vol. 4, no. 1, article 22, 2009.

[18] E. Juhn and A. Khachemoune, "Gardner syndrome: skin manifestations, differential diagnosis and management," American Journal of Clinical Dermatology, vol. 11, no. 2, pp. 117-122, 2010.

[19] H. Benchabane and Y. Ahmed, "The adenomatous polyposis coli tumor suppressor and Wnt signaling in the regulation of apoptosis," Advances in Experimental Medicine and Biology, vol. 656, pp. 75-84, 2009.

[20] M. H. Nieuwenhuis and H. F. A. Vasen, "Correlations between mutation site in APC and phenotype of familial adenomatous polyposis (FAP): a review of the literature," Critical Reviews in Oncology/Hematology, vol. 61, no. 2, pp. 153-161, 2007.

[21] J. R. Sampson and N. Jones, "MUTYH-associated polyposis," Best Practice and Research: Clinical Gastroenterology, vol. 23, no. 2, pp. 209-218, 2009.
[22] N. Al-Tassan, N. H. Chmiel, J. Maynard et al., "Inherited variants of MYH associated with somatic G:C $\rightarrow$ T:A mutations in colorectal tumors," Nature Genetics, vol. 30, no. 2, pp. 227232, 2002.

[23] H. T. Lynch, P. M. Lynch, S. J. Lanspa, C. L. Snyder, J. F. Lynch, and C. R. Boland, "Review of the Lynch syndrome: history, molecular genetics, screening, differential diagnosis, and medicolegal ramifications," Clinical Genetics, vol. 76, no. 1, pp. 1-18, 2009.

[24] H. H. Hare, N. Mahendraker, S. Sarwate, and K. Tangella, "Muir-Torre syndrome: a rare but important disorder," Cutis, vol. 82, no. 4, pp. 252-256, 2008.

[25] Y. Wu, M. J. W. Berends, R. H. Sijmons et al., "A role for MLH3 in hereditary nonpolyposis colorectal cancer," Nature Genetics, vol. 29, no. 2, pp. 137-138, 2001.

[26] T. Hienonen, P. Laiho, R. Salovaara et al., "Little evidence for involvement of MLH3 in colorectal cancer predisposition," International Journal of Cancer, vol. 106, no. 2, pp. 292-296, 2003.

[27] M. E. Kovacs, J. Papp, Z. Szentirmay, S. Otto, and E. Olah, "Deletions removing the last exon of TACSTD1 constitute a distinct class of mutations predisposing to lynch syndrome," Human Mutation, vol. 30, no. 2, pp. 197-203, 2009.

[28] M. J. L. Ligtenberg, R. P. Kuiper, T. L. Chan et al., "Heritable somatic methylation and inactivation of $\mathrm{MSH} 2$ in families with Lynch syndrome due to deletion of the 3' exons of TACSTD1," Nature Genetics, vol. 41, no. 1, pp. 112-117, 2009.

[29] M. Kopacova, I. Tacheci, S. Rejchrt, and J. Bures, "PeutzJeghers syndrome: diagnostic and therapeutic approach," World Journal of Gastroenterology, vol. 15, no. 43, pp. 53975408, 2009.

[30] A. D. Beggs, A. R. Latchford, H. F. A. Vasen et al., "PeutzJeghers syndrome: a systematic review and recommendations for management," Gut, vol. 59, no. 7, pp. 975-986, 2010.

[31] D. E. Jenne, H. Reimann, J. I. Nezu et al., "Peutz-Jeghers syndrome is caused by mutations in a novel serine threonine kinase," Nature Genetics, vol. 18, no. 1, pp. 38-43, 1998.

[32] D. Calva and J. R. Howe, "Hamartomatous polyposis syndromes," Surgical Clinics of North America, vol. 88, no. 4, pp. 779-817, 2008.

[33] L. A. A. Brosens, A. Van Hattem, L. M. Hylind et al., "Risk of colorectal cancer in juvenile polyposis," Gut, vol. 56, no. 7, pp. 965-967, 2007.

[34] J. R. Howe, S. Roth, J. C. Ringold et al., "Mutations in the SMAD4/DPC4 gene in juvenile polyposis," Science, vol. 280, no. 5366, pp. 1086-1088, 1998.

[35] J. R. Howe, J. L. Bair, M. G. Sayed et al., "Germline mutations of the gene encoding bone morphogenetic protein receptor 1A in juvenile polyposis," Nature Genetics, vol. 28, no. 2, pp. 184-187, 2001.

[36] P. Y. Cheah, YU. H. Wong, Y. P. Chau et al., "Germline bone morphogenesis protein receptor 1A mutation causes colorectal tumorigenesis in hereditary mixed polyposis syndrome," American Journal of Gastroenterology, vol. 104, no. 12, pp. 3027-3033, 2009.

[37] E. E. M. Jaeger, K. L. Woodford-Richens, M. Lockett et al., "An ancestral Ashkenazi haplotype at the HMPS/CRAC1 locus on 15q13-q14 is associated with hereditary mixed polyposis syndrome," American Journal of Human Genetics, vol. 72, no. 5, pp. 1261-1267, 2003.

[38] D. Liaw, D. J. Marsh, J. Li et al., "Germline mutations of the PTEN gene in Cowden disease, an inherited breast and thyroid cancer syndrome," Nature Genetics, vol. 16, no. 1, pp. 64-67, 1997. 
[39] C. A. Rubio, S. Stemme, E. Jaramillo, and A. Lindblom, "Hyperplastic polyposis coli syndrome and colorectal carcinoma," Endoscopy, vol. 38, no. 3, pp. 266-270, 2006.

[40] J. Jass, "Hyperplastic polyposis," in Pathology and Genetics of Tumors of the Digestive System, S. R. Hamilton and L. A. Aaltonen, Eds., pp. 135-136, International Agency for Research on Cancer, Lyon, France, 2000.

[41] Y. Gao, Y. Cao, A. Tan, C. Liao, Z. Mo, and F. Gao, "Glutathione S-transferase M1 polymorphism and sporadic colorectal cancer risk: an updating meta-analysis and HuGE review of 36 case-control studies," Annals of Epidemiology, vol. 20, no. 2, pp. 108-121, 2010.

[42] C. Liao, Y. Cao, L. Wu, J. Huang, and F. Gao, "An updating meta-analysis of the glutathione S-transferase T1 polymorphisms and colorectal cancer risk: a HuGE review," International Journal of Colorectal Disease, vol. 25, no. 1, pp. 25-37, 2010.

[43] K. P. Economopoulos and T. N. Sergentanis, "GSTM1, GSTT1, GSTP1, GSTA1 and colorectal cancer risk: a comprehensive meta-analysis," European Journal of Cancer, vol. 46, no. 9, pp. 1617-1631, 2010.

[44] B. Wang, D. Wang, G. Huang, C. Zhang, D. H. Xu, and W. Zhou, "XRCC1 polymorphisms and risk of colorectal cancer: a meta-analysis," International Journal of Colorectal Disease, vol. 25, no. 3, pp. 313-321, 2010.

[45] Z. Jiang, C. Li, YE. Xu, and S. Cai, "A meta-analysis on XRCC1 and XRCC3 polymorphisms and colorectal cancer risk," International Journal of Colorectal Disease, vol. 25, no. 2, pp. 169-180, 2010.

[46] K. Curtin, W. Y. Lin, R. George et al., "Genetic variants in XRCC2: new insights into colorectal cancer tumorigenesis," Cancer Epidemiology Biomarkers and Prevention, vol. 18, no. 9, pp. 2476-2484, 2009.

[47] H. Cao, Z. Xu, H. Long, X.-Q. Li, and S.-L. Li, "The $765 \mathrm{C}$ allele of the cyclooxygenase- 2 gene as a potential risk factor of colorectal cancer: a meta-analysis," Tohoku Journal of Experimental Medicine, vol. 222, no. 1, pp. 15-21, 2010.

[48] J. Dong, J. Dai, M. Zhang, Z. Hu, and H. Shen, "Potentially functional COX-2-1195G $>$ A polymorphism increases the risk of digestive system cancers: a meta-analysis," Journal of Gastroenterology and Hepatology, vol. 25, no. 6, pp. 10421050, 2010.

[49] W. Zhu, B. B. Wei, X. Shan, and P. Liu, "-765G>C and $8473 \mathrm{~T}>\mathrm{C}$ polymorphisms of COX-2 and cancer risk: a metaanalysis based on 33 case-control studies," Molecular Biology Reports, vol. 37, no. 1, pp. 277-288, 2010.

[50] Y. Huang, S. Han, Y. Li, Y. Mao, and Y. Xie, "Different roles of MTHFR C677T and A1298C polymorphisms in colorectal adenoma and colorectal cancer: a meta-analysis," Journal of Human Genetics, vol. 52, no. 1, pp. 73-85, 2007.

[51] K. Yu, J. Zhang, J. Zhang et al., "Methionine synthase A2756G polymorphism and cancer risk: a meta-analysis," European Journal of Human Genetics, vol. 18, no. 3, pp. 370-378, 2010.

[52] M. Sørensen, H. Autrup, A. Olsen, A. Tjønneland, K. Overvad, and O. Raaschou-Nielsen, "Prospective study of NAT1 and NAT2 polymorphisms, tobacco smoking and meat consumption and risk of colorectal cancer," Cancer Letters, vol. 266, no. 2, pp. 186-193, 2008.

[53] M. Gulubova, I. Manolova, J. Ananiev, A. Julianov, Y. Yovchev, and K. Peeva, "Role of TGF- $\beta 1$, its receptor TGF $\beta$ RII, and Smad proteins in the progression of colorectal cancer," International Journal of Colorectal Disease, vol. 25, no. 5, pp. 591-599, 2010.
[54] L. G. Carvajal-Carmona, M. Churchman, C. Bonilla et al., "Comprehensive assessment of variation at the transforming growth factor $\beta$ type 1 receptor locus and colorectal cancer predisposition," Proceedings of the National Academy of Sciences of the United States of America, vol. 107, no. 17, pp. 7858-7862, 2010.

[55] P. Broderick, L. Carvajal-Carmona, A. M. Pittman et al., "A genome-wide association study shows that common alleles of SMAD7 influence colorectal cancer risk," Nature Genetics, vol. 39, no. 11, pp. 1315-1317, 2007.

[56] C. L. Thompson, S. J. Plummer, L. S. Acheson, T. C. Tucker, G. Casey, and ., "Association of common genetic variants in SMAD7 and risk of colon cancer," Carcinogenesis, vol. 30, no. 6, pp. 982-986, 2009.

[57] A. M. Pittman, S. Naranjo, E. Webb et al., "The colorectal cancer risk at $18 \mathrm{q} 21$ is caused by a novel variant altering SMAD7 expression," Genome Research, vol. 19, no. 6, pp. 987-993, 2009.

[58] M. L. Slattery, J. Herrick, K. Curtin et al., "Increased risk of colon cancer associated with a genetic polymorphism of SMAD7," Cancer Research, vol. 70, no. 4, pp. 1479-1485, 2010.

[59] G. Y. Locker, K. Kaul, D. S. Weinberg et al., “The I1307K APC polymorphism in Ashkenazi Jews with colorectal cancer: clinical and pathologic features," Cancer Genetics and Cytogenetics, vol. 169, no. 1, pp. 33-38, 2006.

[60] S. G. Reeves, D. Rich, C. J. Meldrum et al., "IGF1 is a modifier of disease risk in hereditary non-polyposis colorectal cancer," International Journal of Cancer, vol. 123, no. 6, pp. 13391343, 2008.

[61] M. Zecevic, C. I. Amos, X. Gu et al., "IGF1 gene polymorphism and risk for hereditary nonpolyposis colorectal cancer," Journal of the National Cancer Institute, vol. 98, no. 2, pp. 139-143, 2006.

[62] I. P. M. Tomlinson, E. Webb, L. Carvajal-Carmona et al., "A genome-wide association study identifies colorectal cancer susceptibility loci on chromosomes 10p14 and 8q23.3," Nature Genetics, vol. 40, no. 5, pp. 623-630, 2008.

[63] A. Tenesa, S. M. Farrington, J. G.D. Prendergast et al., "Genome-wide association scan identifies a colorectal cancer susceptibility locus on 11q23 and replicates risk loci at 8q24 and 18q21," Nature Genetics, vol. 40, no. 5, pp. 631-637, 2008.

[64] R. S. Houlston, E. Webb, P. Broderick et al., "Meta-analysis of genome-wide association data identifies four new susceptibility loci for colorectal cancer," Nature Genetics, vol. 40, no. 12, pp. 1426-1435, 2008.

[65] J. Lascorz, A. Försti, B. Chen et al., "Genome-wide association study for colorectal cancer identifies risk polymorphisms in German familial cases and implicates MAPK signalling pathways in disease susceptibility," Carcinogenesis, vol. 31, no. 9, pp. 1612-1619, 2010.

[66] A. Russo, V. Bazan, B. Iacopetta, D. Kerr, T. Soussi, and N. Gebbia, "The TP53 colorectal cancer international collaborative study on the prognostic and predictive significance of p53 mutation: influence of tumor site, type of mutation, and adjuvant treatment," Journal of Clinical Oncology, vol. 23, no. 30, pp. 7518-7528, 2005.

[67] B. Iacopetta, A. Russo, V. Bazan et al., "Functional categories of TP53 mutation in colorectal cancer: results of an International Collaborative Study," Annals of Oncology, vol. 17, no. 5, pp. 842-847, 2006.

[68] H. J. N. Andreyev, A. R. Norman, D. Cunningham et al., "Kirsten ras mutations in patients with colorectal cancer: 
the 'RASCAL II' study,' British Journal of Cancer, vol. 85, no. 5, pp. 692-696, 2001.

[69] B. Dutrillaux, "Recent data on the cytogenetics of colorectal adenocarcinoma," Bulletin du Cancer, vol. 75, no. 6, pp. 509$516,1988$.

[70] E. R. Fearon, K. R. Cho, J. M. Nigro et al., "Identification of a chromosome 18q gene that is altered in colorectal cancers," Science, vol. 247, no. 4938, pp. 49-56, 1990.

[71] W. M. Korn, T. Yasutake, W. L. Kuo et al., "Chromosome arm 20q gains and other genomic alterations in colorectal cancer metastatic to liver, as analyzed by comparative genomic hybridization and fluorescence in situ hybridization," Genes Chromosomes and Cancer, vol. 25, no. 2, pp. 82-90, 1999.

[72] P. De Angelis, O. P. F. Clausen, A. Schjølberg, and T. Stokke, "Chromosomal gains and losses in primary colorectal carcinomas detected by CGH and their associations with tumour DNA ploidy, genotypes and phenotypes," British Journal of Cancer, vol. 80, no. 3-4, pp. 526-535, 1999.

[73] M. Hermsen, C. Postma, J. Baak et al., "Colorectal adenoma to carcinoma progression follows multiple pathways of chromosomal instability," Gastroenterology, vol. 123, no. 4, pp. 1109-1119, 2002.

[74] C. B. Diep, K. Kleivi, F. R. Ribeiro, M. R. Teixeira, O. C. Lindgjærde, and R. A. Lothe, "The order of genetic events associated with colorectal cancer progression inferred from meta-analysis of copy number changes," Genes Chromosomes and Cancer, vol. 45, no. 1, pp. 31-41, 2006.

[75] J. Camps, G. Armengol, J. del Rey et al., "Genome-wide differences between microsatellite stable and unstable colorectal tumors," Carcinogenesis, vol. 27, no. 3, pp. 419-428, 2006.

[76] H. Fensterer, B. Radlwimmer, J. Sträter et al., "Matrixcomparative genomic hybridization from multicenter formalin-fixed paraffin-embedded colorectal cancer tissue blocks," BMC Cancer, vol. 7, article 58, 2007.

[77] M. Muleris, A. Chalastanis, N. Meyer et al., "Chromosomal instability in near-diploid colorectal cancer: a link between numbers and structure," PLoS ONE, vol. 3, no. 2, Article ID e1632, 2008.

[78] T. Knutsen, H. M. Padilla-Nash, D. Wangsa et al., "Definitive molecular cytogenetic characterization of 15 colorectal cancer cell lines," Genes Chromosomes and Cancer, vol. 49, no. 3, pp. 204-223, 2010.

[79] C. Lengauer, K. W. Kinzler, and B. Vogelstein, "Genetic instability in colorectal cancers," Nature, vol. 386, no. 6625, pp. 623-627, 1997.

[80] M. Toyota, N. Ahuja, M. Ohe-Toyota, J. G. Herman, S. B. Baylin, and J. P. J. Issa, "CpG island methylator phenotype in colorectal cancer," Proceedings of the National Academy of Sciences of the United States of America, vol. 96, no. 15, pp. 8681-8686, 1999.

[81] M. S. Pino and D. C. Chung, "The chromosomal instability pathway in colon cancer," Gastroenterology, vol. 138, no. 6, pp. 2059-2072, 2010.

[82] W. M. Grady and J. M. Carethers, "Genomic and epigenetic instability in colorectal cancer pathogenesis," Gastroenterology, vol. 135, no. 4, pp. 1079-1099, 2008.

[83] H. Rajagopalan, M. A. Nowak, B. Vogelstein, and C. Lengauer, "The significance of unstable chromosomes in colorectal cancer," Nature Reviews Cancer, vol. 3, no. 9, pp. 695-701, 2003.

[84] P. Duesberg, R. Li, A. Fabarius, and R. Hehlmann, "Aneuploidy and cancer: from correlation to causation," Contributions to Microbiology, vol. 13, pp. 16-44, 2006.
[85] S. D. Markowitz and M. M. Bertagnolli, "Molecular origins of cancer: molecular basis of colorectal cancer," New England Journal of Medicine, vol. 361, no. 25, pp. 2449-2460, 2009.

[86] E. Martinez-Lopez, A. Abad, A. Font et al., "Allelic loss on chromosome $18 \mathrm{q}$ as a prognostic marker in stage II colorectal cancer," Gastroenterology, vol. 114, no. 6, pp. 1180-1187, 1998.

[87] S. N. Thibodeau, G. Bren, and D. Schaid, "Microsatellite instability in cancer of the proximal colon," Science, vol. 260, no. 5109, pp. 816-819, 1993.

[88] Z. Wang, J. M. Cummins, D. Shen et al., "Three classes of genes mutated in colorectal cancers with chromosomal instability," Cancer Research, vol. 64, no. 9, pp. 2998-3001, 2004.

[89] T. D. Barber, K. McManus, K. W. Y. Yuen et al., "Chromatid cohesion defects may underlie chromosome instability in human colorectal cancers," Proceedings of the National Academy of Sciences of the United States of America, vol. 105, no. 9, pp. 3443-3448, 2008.

[90] R. N. Jorissen, L. Lipton, P. Gibbs et al., "DNA copy-number alterations underlie gene expression differences between microsatellite stable and unstable colorectal cancers," Clinical Cancer Research, vol. 14, no. 24, pp. 8061-8069, 2008.

[91] G. Lurje, WU. Zhang, and H. J. Lenz, "Molecular prognostic markers in locally advanced colon cancer," Clinical Colorectal Cancer, vol. 6, no. 10, pp. 683-690, 2007.

[92] S. Ogino, K. Nosho, N. Irahara et al., "Prognostic significance and molecular associations of $18 \mathrm{q}$ loss of heterozygosity: a cohort study of microsatellite stable colorectal cancers," Journal of Clinical Oncology, vol. 27, no. 27, pp. 4591-4598, 2009.

[93] T. Goto, H. Mizukami, A. Shirahata et al., "Aberrant methylation of the p16 gene is frequently detected in advanced colorectal cancer," Anticancer Research, vol. 29, no. 1, pp. 275-277, 2009.

[94] Y. Wettergren, E. Odin, S. Nilsson, G. Carlsson, and B. Gustavsson, "p16INK4a gene promoter hypermethylation in mucosa as a prognostic factor for patients with colorectal cancer," Molecular Medicine, vol. 14, no. 7-8, pp. 412-421, 2008.

[95] M. K. Keyes, H. Jang, J. B. Mason et al., "Older age and dietary folate are determinants of genomic and p16-specific DNA methylation in mouse colon," Journal of Nutrition, vol. 137, no. 7, pp. 1713-1717, 2007.

[96] G. R. Wasson, A. P. McGlynn, H. McNulty et al., "Global DNA and p53 region-specific hypomethylation in human colonic cells is induced by folate depletion and reversed by folate supplementation," Journal of Nutrition, vol. 136, no. 11, pp. 2748-2753, 2006.

[97] A. Bernet, L. Mazelin, M. M. Coissieux et al., "Inactivation of the UNC5C netrin-1 receptor is associated with tumor progression in colorectal malignancies," Gastroenterology, vol. 133, no. 6, pp. 1840-1848, 2007.

[98] S. K. Shin, T. Nagasaka, B. H. Jung et al., "Epigenetic and genetic alterations in Netrin-1 receptors UNC5C and DCC in human colon cancer," Gastroenterology, vol. 133, no. 6, pp. 1849-1857, 2007.

[99] K. Hibi and A. Nakao, "Highly-methylated colorectal cancers show poorly-differentiated phenotype," Anticancer Research, vol. 26, no. 6 B, pp. 4263-4266, 2006.

[100] N. Ramírez, E. Bandrés, A. Navarro et al., "Epigenetic events in normal colonic mucosa surrounding colorectal cancer lesions," European Journal of Cancer, vol. 44, no. 17, pp. 26892695, 2008. 
[101] J. S. Choi, K. H. Kim, Y. K. Jeon et al., "Promoter hypermethylation of the ADAM23 gene in colorectal cancer cell lines and cancer tissues," International Journal of Cancer, vol. 124, no. 6, pp. 1258-1262, 2009.

[102] J. Ying, F. F. Poon, J. Yu et al., "DLEC1 is a functional 3p22.3 tumour suppressor silenced by promoter CpG methylation in colon and gastric cancers," British Journal of Cancer, vol. 100, no. 4, pp. 663-669, 2009.

[103] M. S. Kim, J. Lee, and D. Sidransky, "DNA methylation markers in colorectal cancer," Cancer and Metastasis Reviews, vol. 29, no. 1, pp. 181-206, 2010.

[104] H. Kamiyama, H. Noda, O. Takata, K. Suzuki, Y. Kawamura, and F. Konishi, "Promoter hypermethylation of tumorrelated genes in peritoneal lavage and the prognosis of patients with colorectal cancer," Journal of Surgical Oncology, vol. 100, no. 1, pp. 69-74, 2009.

[105] B. An, Y. Kondo, Y. Okamoto et al., "Characteristic methylation profile in $\mathrm{CpG}$ island methylator phenotype-negative distal colorectal cancers," International Journal of Cancer, vol. 127, no. 9, pp. 2095-2105, 2010.

[106] X. L. Xu, J. Yu, H. Y. Zhang et al., "Methylation profile of the promoter $\mathrm{CpG}$ islands of 31 genes that may contribute to colorectal carcinogenesis," World Journal of Gastroenterology, vol. 10, no. 23, pp. 3441-3454, 2004.

[107] S. Mulero-Navarro and M. Esteller, "Chromatin remodeling factor CHD5 is silenced by promoter $\mathrm{CpG}$ island hypermethylation in human cancer," Epigenetics, vol. 3, no. 4, pp. 210215, 2008.

[108] I. Mazón Peláez, M. Kalogeropoulou, A. Ferraro et al., "Oncogenic RAS alters the global and gene-specific histone modification pattern during epithelial-mesenchymal transition in colorectal carcinoma cells," International Journal of Biochemistry and Cell Biology, vol. 42, no. 6, pp. 911-920, 2010.

[109] S. I. Vlaicu, C. A. Tegla, C. D. Cudrici et al., "Epigenetic modifications induced by RGC-32 in colon cancer," Experimental and Molecular Pathology, vol. 88, no. 1, pp. 67-76, 2010.

[110] M. Yamakuchi, M. Ferlito, and C. J. Lowenstein, "miR-34a repression of SIRT1 regulates apoptosis," Proceedings of the National Academy of Sciences of the United States of America, vol. 105, no. 36, pp. 13421-13426, 2008.

[111] M. Liu and H. Chen, "The role of microRNAs in colorectal cancer," Journal of Genetics and Genomics, vol. 37, no. 6, pp. 347-358, 2010.

[112] S. A. Melo and M. Esteller, "Dysregulation of microRNAsin cancer: playing with fire," FEBS Letters. In press.

[113] M. L. Slattery, J. D. Potter, W. Samowitz, D. Schaffer, and M. Leppert, "Methylenetetrahydrofolate reductase, diet, and risk of colon cancer," Cancer Epidemiology Biomarkers and Prevention, vol. 8, no. 6, pp. 513-518, 1999.

[114] A. J. Levine, K. D. Siegmund, C. M. Ervin et al., "The methylenetetrahydrofolate reductase $677 \mathrm{C} \rightarrow \mathrm{T}$ polymorphism and distal colorectal adenoma risk," Cancer Epidemiology Biomarkers and Prevention, vol. 9, no. 7, pp. 657-663, 2000.

[115] T. Keku, R. Millikan, K. Worley et al., "5,10-Methylenetetrahydrofolate reductase codon 677 and 1298 polymorphisms and colon cancer in African Americans and whites," Cancer Epidemiology Biomarkers and Prevention, vol. 11, no. 12, pp. 1611-1621, 2002.

[116] S. Kang, J. W. Kim, G. H. Kang et al., "Polymorphism in folate- and methionine-metabolizing enzyme and aberrant CpG island hypermethylation in uterine cervical cancer," Gynecologic Oncology, vol. 96, no. 1, pp. 173-180, 2005.
[117] A. M. Eaton, R. Sandler, J. M. Carethers, R. C. Millikan, J. Galanko, and T. O. Keku, "5,10-Methylenetetrahydrofolate reductase 677 and 1298 polymorphisms, folate intake, and microsatellite instability in colon cancer," Cancer Epidemiology Biomarkers and Prevention, vol. 14, no. 8, pp. 2023-2029, 2005.

[118] K. Curtin, M. L. Slattery, C. M. Ulrich et al., "Genetic polymorphisms in one-carbon metabolism: associations with CpG island methylator phenotype (CIMP) in colon cancer and the modifying effects of diet," Carcinogenesis, vol. 28, no. 8, pp. 1672-1679, 2007.

[119] B. Iacopetta, J. Heyworth, J. Girschik, F. Grieu, C. Clayforth, and L. Fritschi, "The MTHFR C677T and $\triangle$ DNMT3B C149T polymorphisms confer different risks for right- and left-sided colorectal cancer," International Journal of Cancer, vol. 125, no. 1, pp. 84-90, 2009.

[120] T. Yamaji, M. Iwasaki, S. Sasazuki, H. Sakamoto, T. Yoshida, and S. Tsugane, "Methionine synthase A2756G polymorphism interacts with alcohol and folate intake to influence the risk of colorectal adenoma," Cancer Epidemiology Biomarkers and Prevention, vol. 18, no. 1, pp. 267-274, 2009.

[121] S. De Vogel, K. A. D. Wouters, R. W. H. Gottschalk et al., "Genetic variants of methyl metabolizing enzymes and epigenetic regulators: associations with promoter $\mathrm{CpG}$ island hypermethylation in colorectal cancer," Cancer Epidemiology Biomarkers and Prevention, vol. 18, no. 11, pp. 3086-3096, 2009.

[122] P. Karpinski, A. Myszka, D. Ramsey et al., "Polymorphisms in methyl-group metabolism genes and risk of sporadic colorectal cancer with relation to the $\mathrm{CpG}$ island methylator phenotype," Cancer Epidemiology, vol. 34, no. 3, pp. 338-344, 2010.

[123] M. Nyström and M. Mutanen, "Diet and epigenetics in colon cancer," World Journal of Gastroenterology, vol. 15, no. 3, pp. 257-263, 2009.

[124] M. Esteller, "Epigenetics in evolution and disease," The Lancet, vol. 372, pp. 590-596, 2008.

[125] W. Du, W.-Y. Li, R. Lu, and J.-Y. Fang, "Folate and fiber in the prevention of colorectal cancer: between shadows and the light," World Journal of Gastroenterology, vol. 16, no. 8, pp. 921-926, 2010.

[126] B. Van Guelpen, J. Hultdin, I. Johansson et al., "Low folate levels may protect against colorectal cancer," Gut, vol. 55, no. 10, pp. 1461-1466, 2006.

[127] P. Mokarram, K. Kumar, H. Brim et al., "Distinct high-profile methylated genes in colorectal cancer," PLoS ONE, vol. 4, no. 9, Article ID e7012, 2009.

[128] Y. I. Kim, "Folate and colorectal cancer: an evidence-based critical review," Molecular Nutrition and Food Research, vol. 51, no. 3, pp. 267-292, 2007.

[129] J. B. Mason, A. Dickstein, P. F. Jacques et al., "A temporal association between folic acid fortification and an increase in colorectal cancer rates may be illuminating important biological principles: a hypothesis," Cancer Epidemiology Biomarkers and Prevention, vol. 16, no. 7, pp. 1325-1329, 2007.

[130] J. M. Phelip, V. Ducros, J. L. Faucheron, B. Flourie, and X. Roblin, "Association of hyperhomocysteinemia and folate deficiency with colon tumors in patients with inflammatory bowel disease," Inflammatory Bowel Diseases, vol. 14, no. 2, pp. 242-248, 2008.

[131] S. De Vogel, V. Dindore, M. Van Engeland, R. A. Goldbohm, P. A. Van Den Brandt, and M. P. Weijenberg, "Dietary folate, methionine, riboflavin, and vitamin B-6 and risk of sporadic 
colorectal cancer," Journal of Nutrition, vol. 138, no. 12, pp. 2372-2378, 2008.

[132] S. H. Zeisel, "Gene response elements, genetic polymorphisms and epigenetics influence the human dietary requirement for choline," IUBMB Life, vol. 59, no. 6, pp. 380-387, 2007.

[133] A. Hamid, M. Kiran, S. Rana, and J. Kaur, "Low folate transport across intestinal basolateral surface is associated with down-regulation of reduced folate carrier in in vivo model of folate malabsorption," IUBMB Life, vol. 61, no. 3, pp. 236-243, 2009.

[134] R. P. Arasaradnam, D. M. Commane, D. Bradburn, and J. C. Mathers, "A review of dietary factors and its influence on DNA methylation in colorectal carcinogenesis," Epigenetics, vol. 3, no. 4, pp. 193-198, 2008.

[135] M. Van Engeland, M. P. Weijenberg, G. M. J. M. Roemen et al., "Effects of dietary folate and alcohol intake on promoter methylation in sporadic colorectal cancer: the Netherlands cohort study on diet and cancer," Cancer Research, vol. 63, no. 12, pp. 3133-3137, 2003.

[136] B. C. Paun, D. Kukuruga, Z. Jin et al., "Relation between normal rectal methylation, smoking status, and the presence or absence of colorectal adenomas," Cancer, vol. 116, no. 19, pp. 4495-4501, 2010.

[137] M. L. Slattery, K. Curtin, C. Sweeney et al., "Diet and lifestyle factor associations with $\mathrm{CpG}$ island methylator phenotype and BRAF mutations in colon cancer," International Journal of Cancer, vol. 120, no. 3, pp. 656-663, 2007.

[138] S. E. Olivo-Marston, S. D. Hursting, J. Lavigne et al., "Genetic reduction of circulating insulin-like growth factor1 inhibits azoxymethane-induced colon tumorigenesis in mice," Molecular Carcinogenesis, vol. 48, no. 12, pp. 10711076, 2009.

[139] L. A. E. Hughes, P. A. van den Brandt, A. P. de Bruïne et al., "Early life exposure to famine and colorectal cancer risk: a role for epigenetic mechanisms," PLoS ONE, vol. 4, no. 11, Article ID e7951, 2009.

[140] B. M. Corfe, E. A. Williams, J. P. Bury et al., "A study protocol to investigate the relationship between dietary fibre intake and fermentation, colon cell turnover, global protein acetylation and early carcinogenesis: the FACT study," BMC Cancer, vol. 9, article 332, 2009.

[141] F. Michor, Y. Iwasa, C. Lengauer, and M. A. Nowak, "Dynamics of colorectal cancer," Seminars in Cancer Biology, vol. 15, no. 6, pp. 484-493, 2005. 

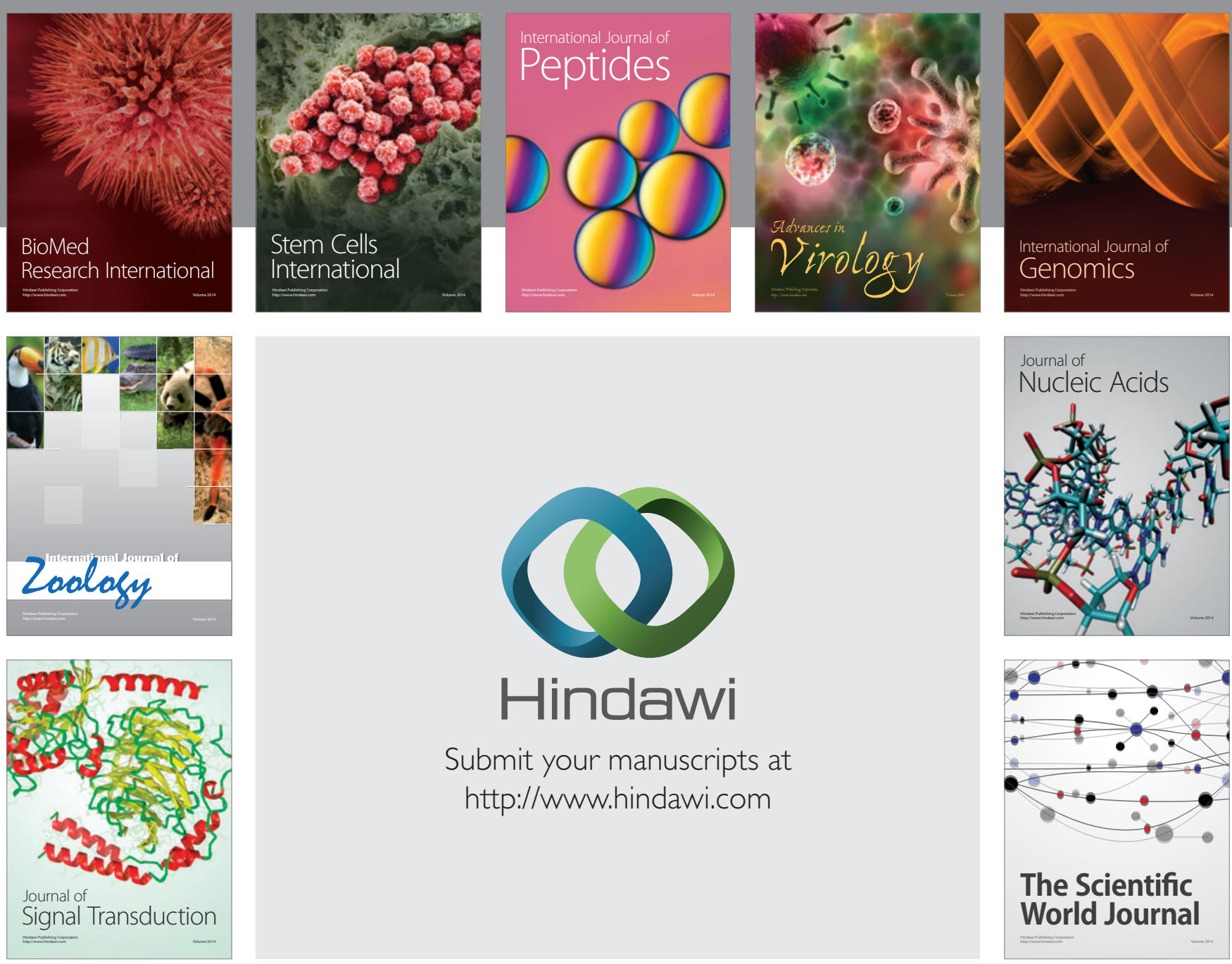

Submit your manuscripts at

http://www.hindawi.com
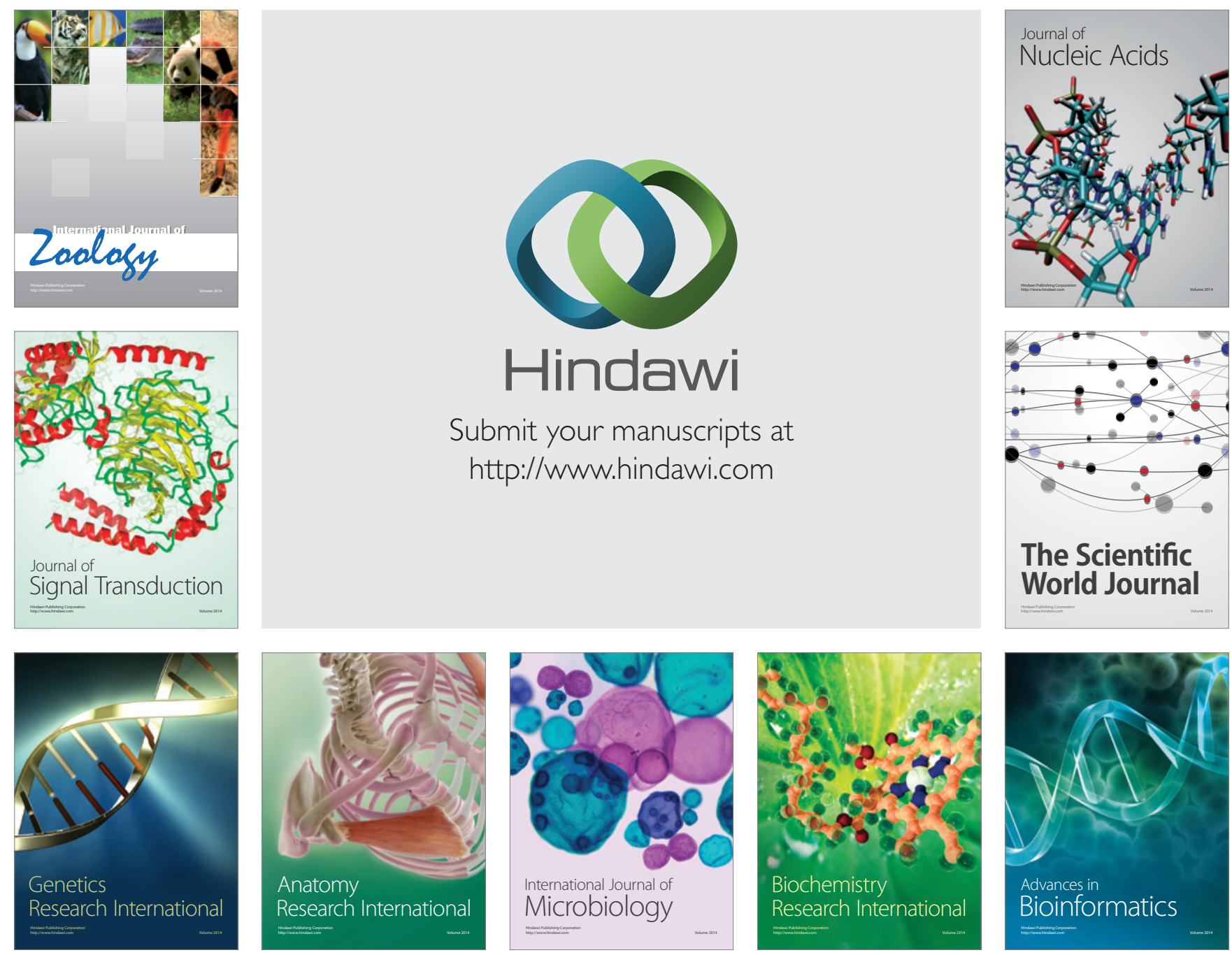

The Scientific World Journal
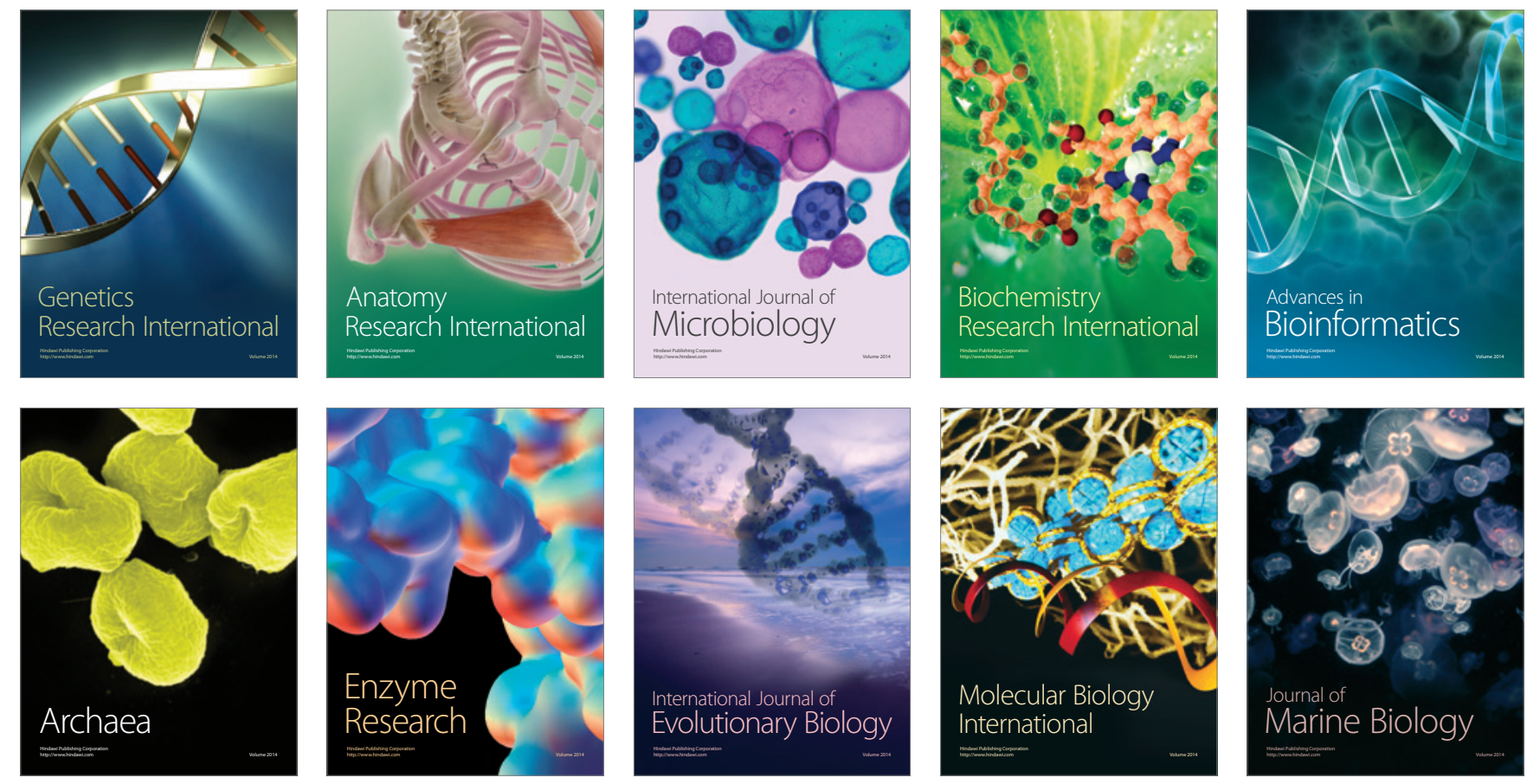